This is the accepted version of Umar, Tariq, Egbu, Charles, Ofori, George, Honnurvali, Mohamed Shaik, Saidani, Messaoud and Opoku, Alex (2019) "High fatalities risk found in gulf construction". International Journal of Sustainable Real Estate and Construction Economics, 1(4), pp. 351-376. ISSN (print) 2059-7770, available at https://doi.org/10.1504/IJSRECE.2019.106544 


\title{
High Fatalities Risk Found in Gulf Construction
}

\author{
Tariq Umar* \\ Lecturer, Civil Engineering, College of Engineering, \\ A'Sharqiyah University, Ibra, Oman \\ E-mail: tariqumar1984@gmail.com \\ https://orcid.org/0000-0002-1197-8181 \\ * Corresponding Author

\section{Charles Egbu} \\ Pro-Vice Chancellor (Education and Experience) \\ University of East London, UK \\ E-mail: C.Egbu@uel.ac.uk

\section{George Ofori} \\ Director of Research, School of Built Environment and Architecture \\ London South Bank University, UK \\ E-mail: oforig3@ 1sbu.ac.uk
}

\section{Mohamed Shaik Honnurvali}

Lecturer, College of Engineering

A'Sharqiyah University, Ibra, Oman

E-mail: m.shaik@asu.edu.om

\section{Messaoud Saidani}

Head of Research, School of Energy, Construction and Environment

Faculty of Engineering, Environment and Computing,

Coventry University, UK

E-mail: cbx086@ coventry.ac.uk

\author{
Alex Opoku \\ Associate Professor, UCL Bartlett School of Construction \& Project Management, \\ University College London, London-UK \\ E-mail: alex.opoku@ucl.ac.uk
}

\begin{abstract}
:
It is predicted that the construction industry will be growing in the future, and that could lead to an increase in risks in work safety and accidents. This paper presents the current status of occupational safety and health in the Gulf region by providing a comparison with those of some of the most advanced countries in the world. According to our data, the Gulf countries have a poor record of work safety and health. Therefore, this research aimed to identify the main factors
\end{abstract}


and provide some solutions for key areas, so that the construction industry could improve its safety performance. Our findings from the literature and from the semi-structured interviews held with the selected professionals suggest that the major areas are: lack of awareness of the importance of safety and costs resulting from accidents; environmental and climatic factors; implementation of rules for developing a culture of harmless working conditions.

\section{Keywords: Project Management, Construction Management, Safety \& hazards, Management, Health \& Safety, Heat Stress, Safety Climate, Health Factors, Systematic Review, GCC Countries.}

Biographical notes: Tariq Umar has completed his Ph.D. degree in Construction Management from London South Bank University, UK and registered as a Chartered Civil Engineer (CEng)/ International Professional Engineer (IntPE) with Engineering Council UK. He has more than 15 years of academic research and teaching experience and has published several research articles in the area of construction management, renewable energy, engineering sustainability, construction materials, and waste and resource management. Additionally, he has served in the civil engineering industry for 4 years. He is an approved mentor of the Institution of Civil Engineers (ICE, UK) and a member of the ICE Oman management committee. He is also serving as member of the editorial board/advisor for a number of journals. His research interest includes but not limited to, Construction Management, Safety and Health, Engineering Sustainability, Construction Materials, Renewable Energy, and Waste and Resources Management.

Professor Charles Egbu is Pro-Vice Chancellor (Education \& Experience) at the University of East London, England, UK. He was formerly the Dean of School of the Built Environment and Architecture, London South Bank University, UK, where he held the Chair in Project Management and Strategic Management in Construction. He has also held academic posts at University College London (UCL), University of Salford, Leeds Metropolitan University, and Glasgow Caledonian University. He has contributed over 350 publications in various international journals and conferences and has hosted, chaired and spoken at many conferences in his areas of expertise. 
Prof. Ofori specialises in Construction Management and Economics, at the project, company and industry levels. His main subject of research is the improvement of the capacity and capability of the construction industry, especially in developing countries. Prof. Ofori was educated at the University of Science and Technology in Kumasi, Ghana where he obtained a BSc (Building Technology in Quantity Surveying). He worked briefly in that university as a Teaching Assistant before proceeding to the UK to study for an MSc (Building Economics and Management) (Distinction) degree at University College London, from where he also obtained a Ph.D. degree in 1981.

Mr. Mohamed Shaik Honnur Vali is currently a lecturer in the Electronics and Communication Department, College of Engineering at A'Sharqiyah University, Sultanate of Oman. He has four years of experience in academics and research with several international journals and conference publications. His research interests are renewable energies, smart cities, wireless communications. He is a member of the institution of Engineers (UK) and is working towards his professional registration with the engineering council. Prior to joining academics, he has an industrial experience of two years. He is also serving as IET Young Professionals Mentor in the Oman section.

After completing his first degree in Civil Engineering, Messaoud embarked on a Ph.D. in Structural Engineering at The University of Nottingham, which he successfully completed in 1991. He then stayed on as a post-doctoral research fellow working on a number of panEuropean and UK projects. He joined Coventry University in 1995 where is currently a Reader and Head of Research in the School of Energy, Construction and Environment. Messaoud is a Chartered Engineer and Member of the Institution of Structural Engineers, with over 25 years' experience in teaching, research, and consultancy. He is the author of over 100 papers and technical reports.

Dr. Alex Opoku is currently an Associate Professor in Project Management and Quantity Surveying at the Bartlett School of Construction \& Project Management, University College London (UCL). He is a Fellow of the Higher Education Academy (FHEA), Chartered Quantity Surveyor (MRICS) and Chartered Construction Manager (MCIOB) with experience in the UK 
Higher Education sector. His research interest is in the area of Sustainable Built Environment with publication in various high impact academic journals. His current research project focuses on the link between the Sustainable Development Goals (SDGs) and the Built Environment.

\section{The Construction Industry:}

Today, the construction industry is not only contributing to the social and economic development of countries but is also a major industry around the world that provides jobs to millions of people and contributes to the economy of countries and the whole world. This fact has been confirmed by different studies, including Beven (2010), Umar and Egbu (2018-a). The construction industry is further reported to be contributing a major portion of the gross domestic product (GDP) in different countries. For instance, it is 6.10\% in the United Kingdom, 5.50\% in Japan and 9.0\% in Oman (ONS, 2017; SHJ, 2017; NCSI, 2017). Only, in the European Union (EU), the construction sector provides jobs to approximately 18 million people and contributes up to $9 \%$ of the total EU's GDP (EUCS, 2016). Globally, the construction industry employs 7\% of the total world's workforce and accumulates 13\% of the global GDP (Deloitte, 2017). Due to the nature of the work, there are normally more employment opportunities in construction companies. For example, in the United Kingdom, there are 296,096 construction firms that employ approximately 2,731,370 people, giving a firm to employment ratio of 1:11 (Statista, 2018). The world population review shows the UK population in 2018 was 66,723,105. Thus, the percentage of construction workers in the UK was $4 \%$ of the total population in 2018. Similarly, in Australia, employment in the construction industry rose from 1.0 million people to 1.10 million within a year (from November 2016 to November 2017), resulting in an employment increase rate of $8.5 \%$ (Parliament of Australia, 2018). During the same period, the percentage of employment in construction in Australia (out of the total employment) rose from $8.9 \%$ to $9.4 \%$ (figure 2). The total population in Australia by the end of 2017 was 24.6 million, thus the percentage of the population employed in construction in 2017 stood at 5\% (ABS, 2018). Similarly, the statistics of the United States show that in September 2018, employment in the construction industry was 7,286,000 representing $2.23 \%$ of the total population. Apart from this, the USA Census Bureau data shows that a total of US \$1,329,452 million spent on construction only in the month of September of 2018 (Census Bureau, 2018). The value of the private 
construction spending was the highest which stood at 1,020,358 Million US \$ as shown in table 1.

It is expected that the construction industry will be more than double in size (of 2010) by 2020 . This represents a growth rate of $110 \%$, which will make the construction industry worth $\$ 7$ trillion. This growth further translates into an overall proportion of $17.2 \%$ of the GDP in 2020 (Beven, 2010). Similarly, another forecast indicated that the global construction industry will reach 14 trillion US\$ in 2025 from 9.5 trillion US\$ in 2014, reflecting a 67\% growth as shown in figure 1 (Statista, 2017). Although both forecasts estimate a different value of the growth, what is evident clearly is that the construction industry is rapidly growing. The growth in the construction industry is further expected to continue as this industry needs to address some of the key challenges faced by human. These challenges are outlined by many international organizations. For example, a report published by the World Resources Institute (WRI) shows that approximately 1.2 billion people in urban areas around the world do not have access to affordable housing. The report further indicates that this number will rise by $30 \%$ by 2025 , and will reach to 1.60 billion people (WRI, 2017). Similarly, the World Health Organization (WHO) report published in 2017 shows that 2.1 billion people have no access to clean and reliable water. The people, who have no access to clean sanitation, stand at 4.5 billion (WHO, 2017). These challenges clearly indicate that the growth of the construction industry will be mandatory to address these issues. 


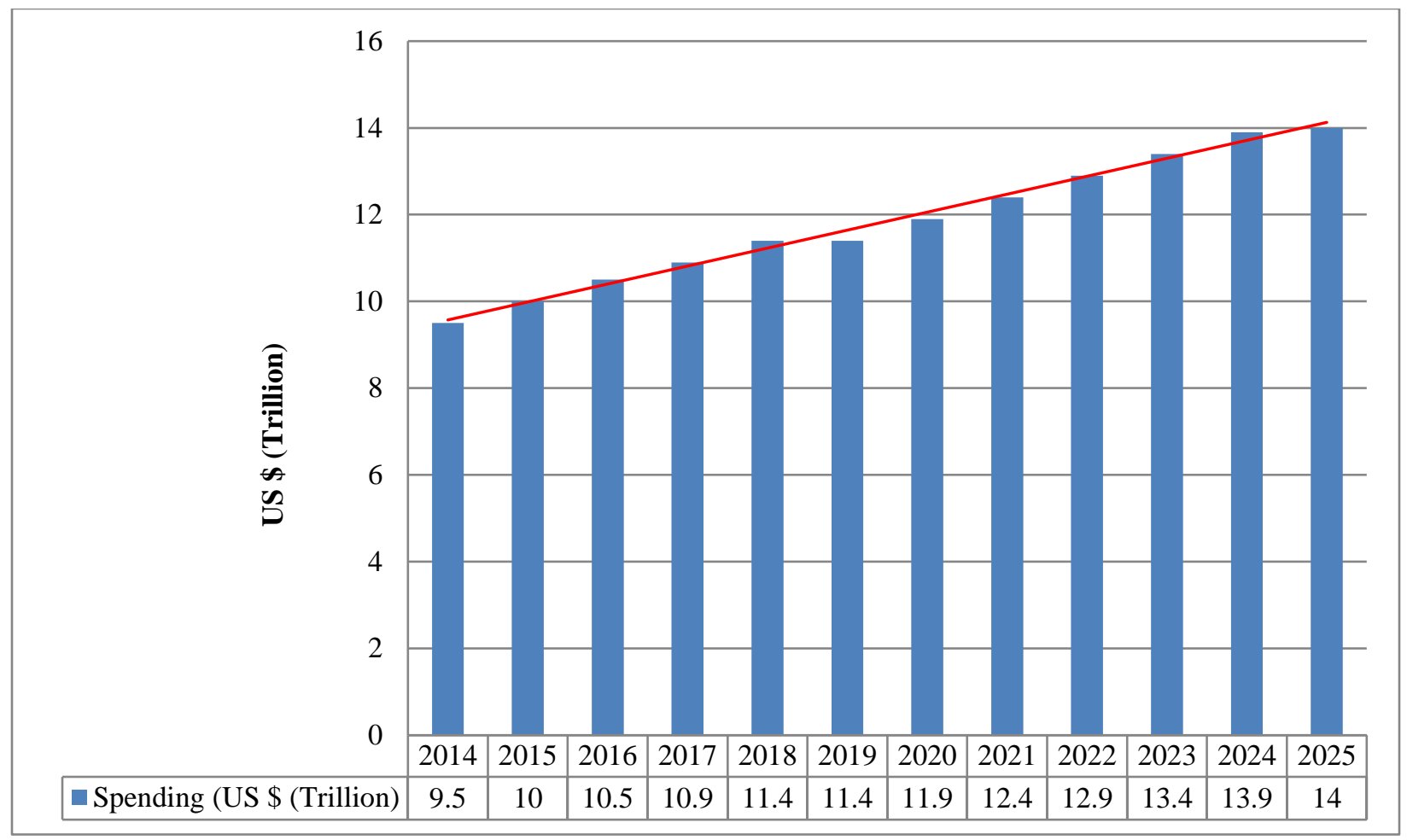

Figure 1: Global Construction Industry Growth (Statista, 2017).

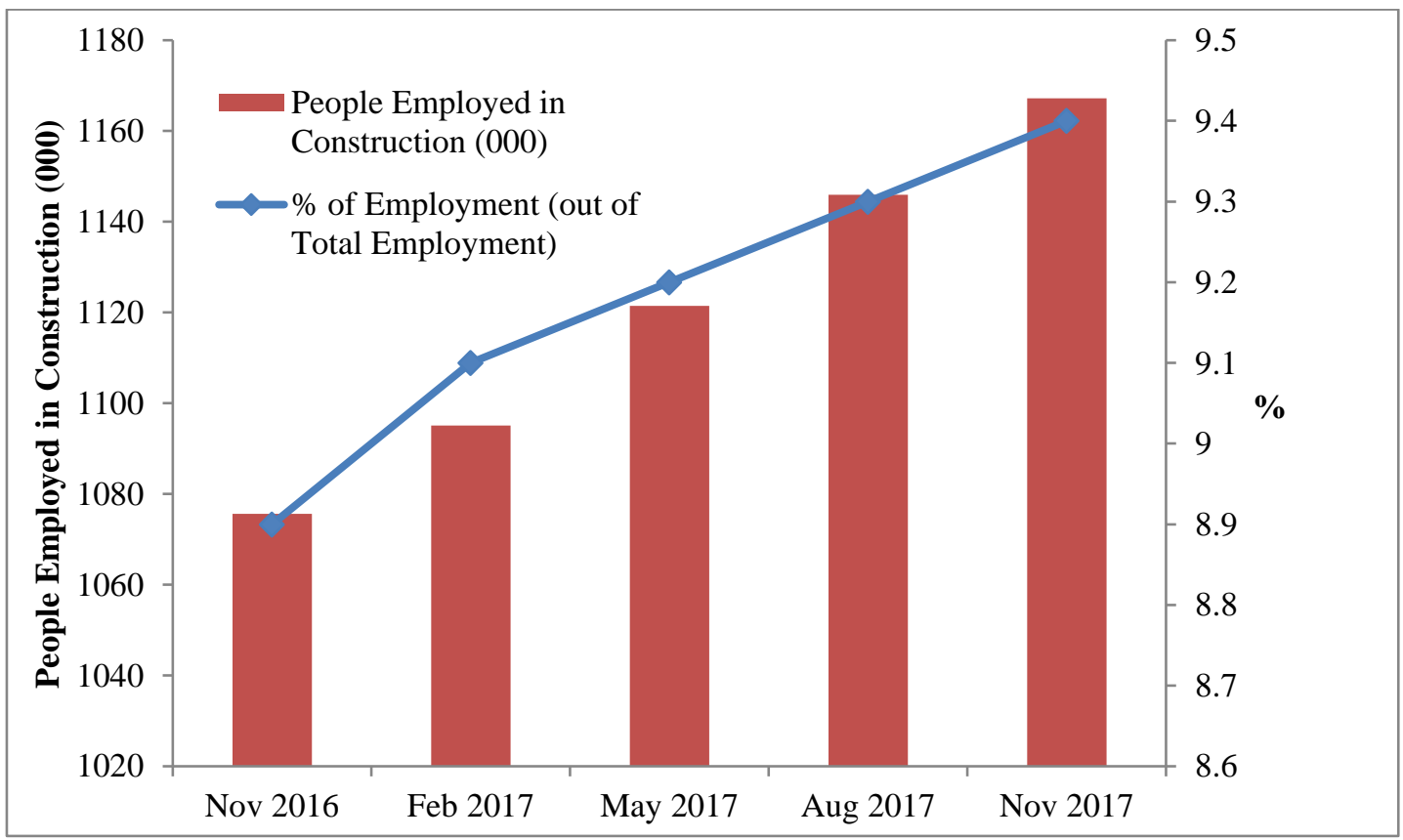

Figure 2: Employment in the Australian Construction Industry. 


\begin{tabular}{|l|r|}
\hline Construction Sector & Sending (US\$ Million) \\
\hline Private (Residential) & 556,424 \\
\hline $\begin{array}{l}\text { Private } \\
\text { (Nonresidential) }\end{array}$ & 463,934 \\
\hline $\begin{array}{l}\text { Public (State and } \\
\text { Local) }\end{array}$ & 288,112 \\
\hline Public (Federal) & 20,982 \\
\hline Total & $\mathbf{1 , 3 2 9 , 4 5 2}$ \\
\hline
\end{tabular}

Table 1: Value of Construction Work Done in September 2018 in USA.

With all these growths, the construction industry is regarded as one of the hazardous industries where the number of accidents resulting injuries and fatalities is comparatively high ( $\mathrm{Li}$ and Poon, 2013; Umar et al., 2019). Site safety is not only a big issue during new construction projects but it is also one of the critical factors affecting the sustainability of skyscrapers and decoration, repair, and maintenance projects ( $\mathrm{Li}$ et al., 2019). The risk associated with this industry in the developing countries is further high as compared with the developed countries. This article, therefore, aims to investigate the status of the construction industry in the Gulf Cooperation Council (GCC) region with an emphasis on safety performance. The article further aims to propose some areas which can be helpful to improve the safety performance of the construction industry in the region. The methodology adopted for this purpose is explained in the next section.

\section{Research Methodology:}

Generally, the research methods in construction management are broadly divided into two categories known as quantitative and qualitative research methods (Umar and Egbu, 2018; Umar et al., 2019-a). Considering the nature of this research, a qualitative research approach was deemed fit to achieve set aims and objectives. The required data were collected in two different stages. The data related to the GCC construction industry, safety and health in construction particularly in the GCC region and methods to improve the safety performance in construction were collected using systematic literature review. A similar approach was also adopted by Wu et al., (2019) in their study related to the impacts of lean construction on safety systems. Different databases including Web of Science, Scopus, Proquest and Science Direct were used for the systematic review. The search period was kept from 2000 to 2019. The keywords used for the dataset search were GCC construction industry, Safety, and Health in Construction, Safety 
Performance, Accidents, Injuries, and Fatalities. The reports related to the construction industry presenting the statistics related to safety and health published by the authoritative organizations were also considered in this review process. Preferred reporting items for systematic reviews and meta-analyses (PRISMA) guidelines adhered during this review process (Moher, 2009; Umar, 2019; Umar et al., 2019-b). In the second part of the research, semi-structured interviews were conducted with the selected participants. The aim of this interview was to investigate how much the methods for the improvement of safety performance found through systematic review could be effective in the GCC construction. This was achieved through a total of 12 interviews with the selected respondents from academics and industry. Six interviewees were selected from academic and six from the construction industry. Interviews within Oman were conducted faceto-face, while interviews from other GCC countries were conducted telephonically. The interviewees were selected in a way so that more accurate and reliable information could be obtained. Academic interviewees were selected from across the GCC countries representing the top leading universities. The condition for academic interviewees was that respondents should be at the rank of full-time professor with a research interest in construction management. The interviewee should have their academic qualifications in civil or a closer field of engineering. Likewise, the interviewees from the industry were also selected from all over GCC countries representing the leading construction organizations. The respondents were chosen on the criteria that they must be at a managerial role who have safety-related responsibilities. The minimum experience at managerial roles for interviewees was set as 10 years. Their organizations must be registered as an excellent grade company in any GCC country and should be able to participate in all tenders in that country. During the interview process, the interviewees were given an insight into the current research with the key areas to improve safety and health in the GCC construction.

The next section presents the result and discussion on different parameters of the research.

\section{Results and Discussion:}

A total of 137 papers and reports were downloaded during the systematic review process. After adopting the screening process, 69 papers and reports were rejected, thus the total number of papers and reports considered in this paper stand at 68. Considering different parameters of the 
research, the results and discussion are divided into several parts. The first part provides an overview of the GCC construction industry.

\subsection{GCC's Construction Industry:}

There are five-member countries of the GCC, which includes Saudi Arabia, Oman, Qatar, Bahrain, and Kuwait. The economy of the region is heavily reliant on the oil and gas exports that constitute more than 50\% of its GDP (Umar and Wamuziri, 2016-a; Umar, 2017-a; Umar, 2018). Despite the dip in oil prices in recent years and its negative impact on the GCC countries' economy, investment in infrastructure projects continues to increase. This is clearly evident from the value of the planned and ongoing construction projects in all GCC countries, which was 1,300 billion in the year 2015, as shown in figure 3 (Deloitte, 2015). Similarly, a report published in Arabian Business (AB, 2017) in late 2017 indicates that there were 20,000 active construction projects worth US\$2.4 trillion. According to Oman's budget report, the spending on development projects was estimated at US\$ 3.12 billion ( 1.20 billion Omani Rial), representing the amount to paid during the year 2017 as the actual work progressed (TOM, 2017). A comparison of the contracts awarded in the GCC countries, in the first quarter of 2017 with those awarded in 2018 shows an overall decline of US \$ 5.0 Billion as shown in figure 4 (Ventures, 2018). While there is an impact on the construction industry due to the economic situation, different studies have shown that the construction industry will continue to grow in the near future. Umar et al., (2018) while discussing the occupational safety and health regulations, reported that the value of the construction industry in Oman will grow to 6.88 billion Omani Rial, which was 2.26 billion Omani Rial in 2016. Moreover, the construction GDP in Oman is forecasted to grow to $15.4 \%$ of the total GDP by 2026. Overall, they reported that the construction growth rate is forecasted to reach its peak in 2020 (figure 5). 


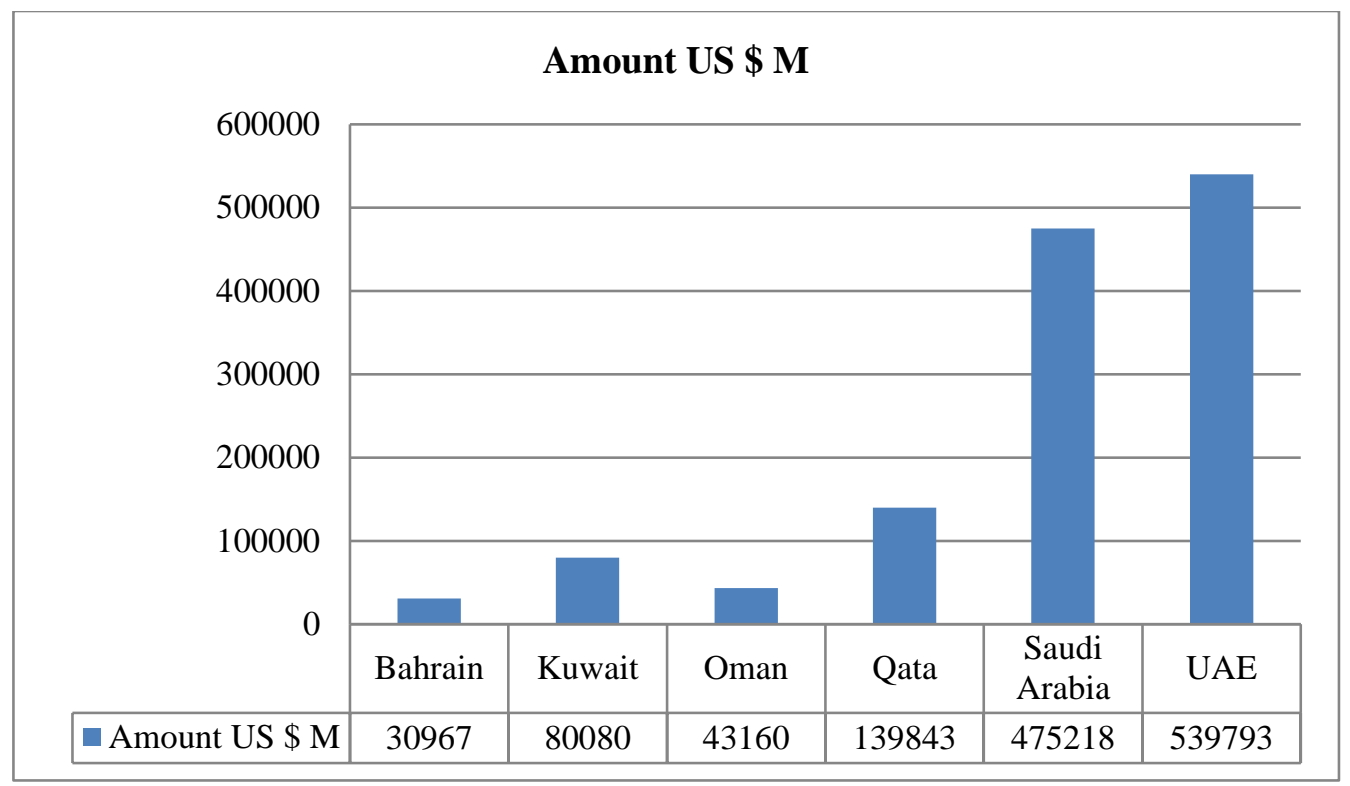

Figure 3: Planned and Ongoing Construction Projects in Oman (Deloitte, 2015; Umar et al., 2019-c)

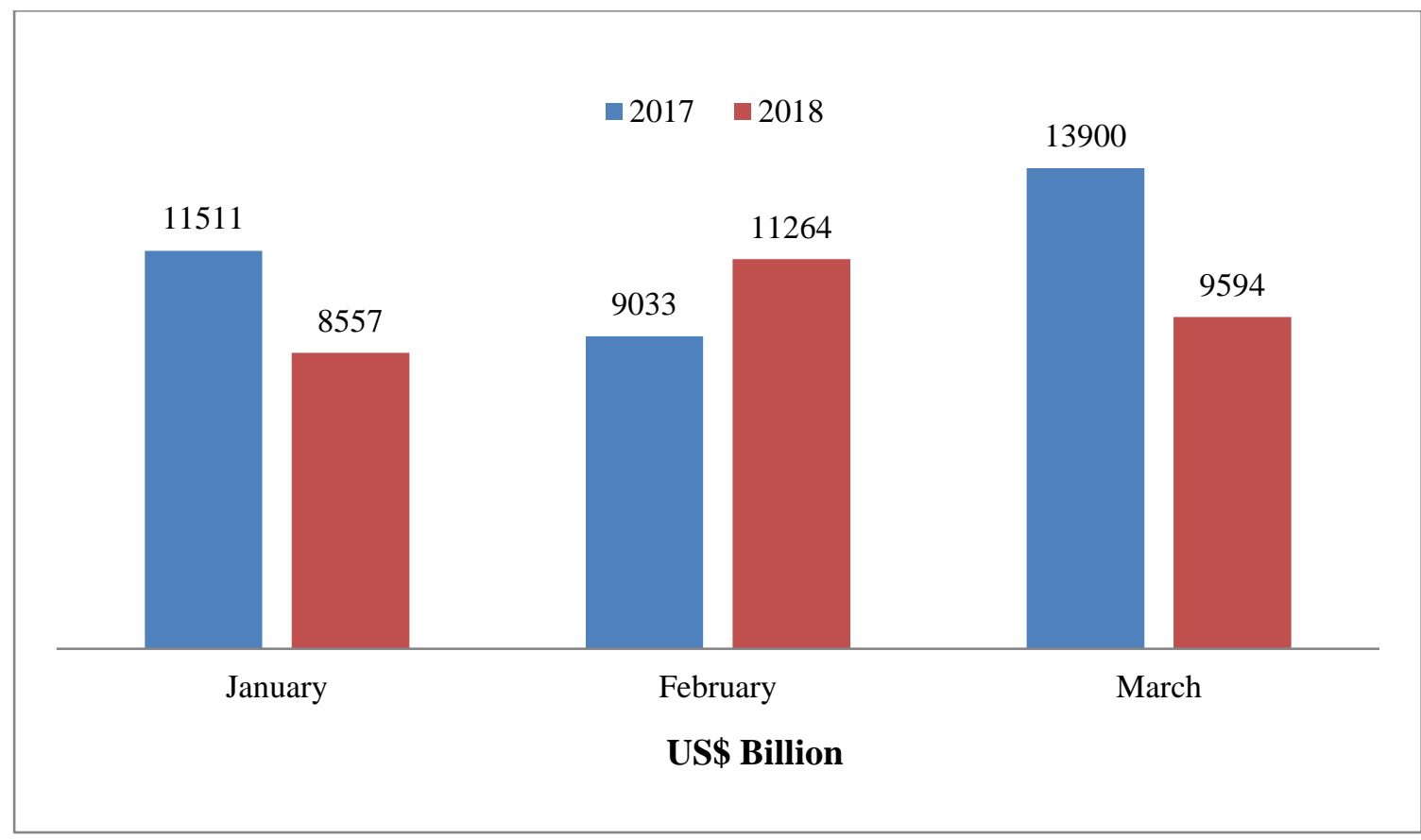

Figure 4: Comparison of Awarded Construction Contracts in GCC (Ventures, 2018; Umar et al., 2018-a). 


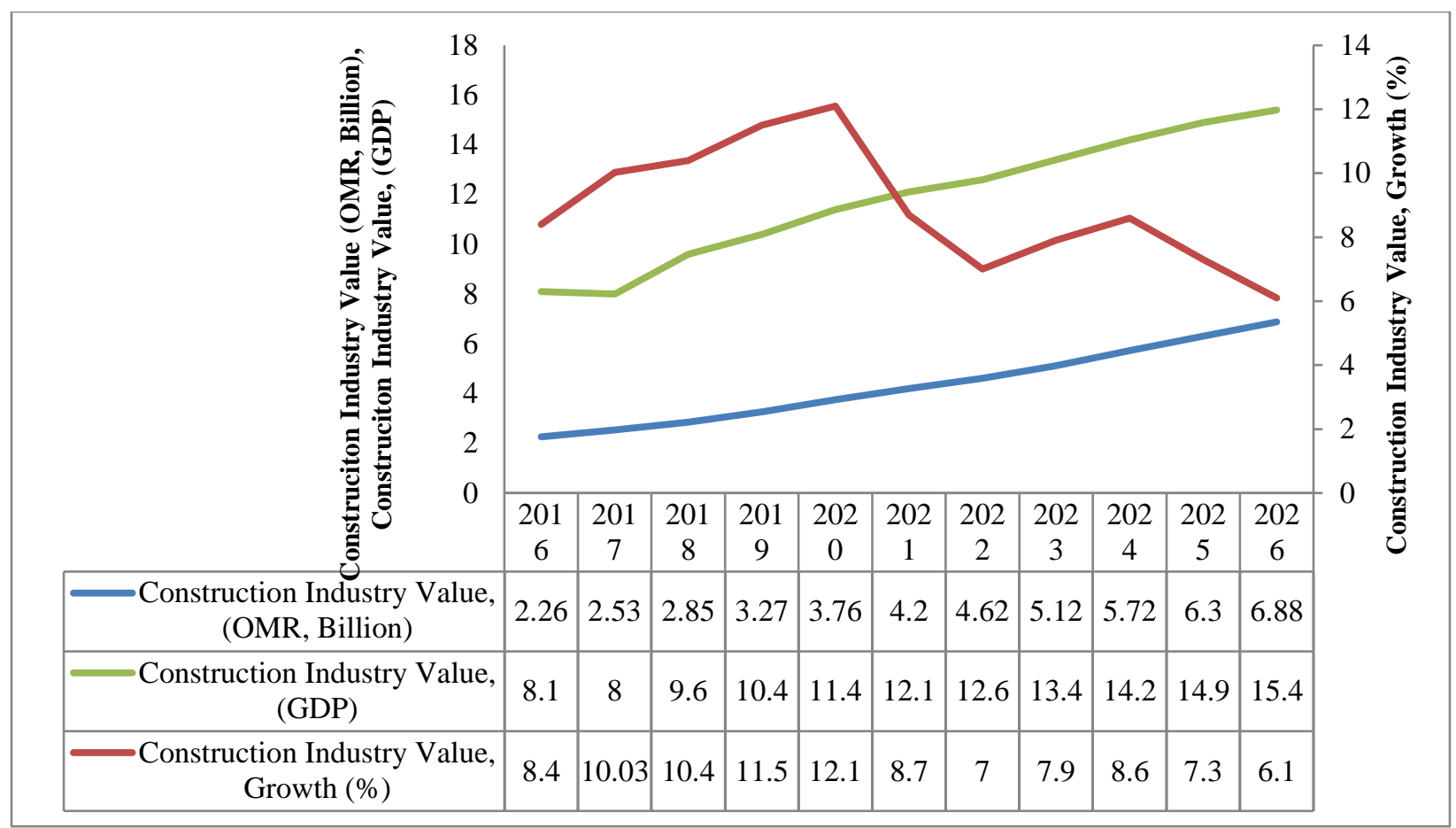

Figure 5: Oman Infrastructure and Construction Industry Forecasts (2016-2026).

The GCC countries are highly dependent on foreign workforce. Statistics published by the GCC Centre for Statistics show that the number of expatriate workers in the GCC countries was 13.86 million by the end of December 2017, accounting for $69.3 \%$ of the total workforce in these countries (GCC Stat, 2018). Most of these workers are from Asian and African countries. For example, workers from Bangladesh constitute the largest group of expatriate workers in Oman (NCSI, 2017-b). The total population of Oman in 2018 was 4,655,435 with an expatriate population of 2,047,788 making up $44 \%$ of the total Omani population (PC, 2018). In 2016, the construction workforce in Oman was approximately 725,000; out of which $92 \%$ were foreign workers (Umar, 2016). The construction workforce, therefore, represented $16 \%$ of the total population of Oman in 2016. These calculations are the official data, which represent the workers who have a work permit related to the construction profession. It is possible that the actual number of the workforce in construction may be higher than what is quoted in their study. To represent an insight of the GCC's construction workers, figure 6 shows the classifications of foreigner workers in the construction industry in Oman (OSC, 2016). Similarly, the data related to the United Arab Emirates workforce for the year 2018 is shown in table 2, which represents the number of establishments by economic sectors and the workforce in each sector. This data 
clearly shows that the construction industry is on the top of the list by providing jobs to more than 500 million peoples with a total number of establishments of 65,419 followed by the trade and repair sector. The employment ratio between number of establishments and the employed workers for construction stood at 1:26, while the same ratio for trade and repair sector stood at 1:16. This clearly reflects that the construction sector establishments in the United Arab Emirates provide more jobs (1.62 times more) per establishment compared to the trade and repair sector (MHRE, 2018).

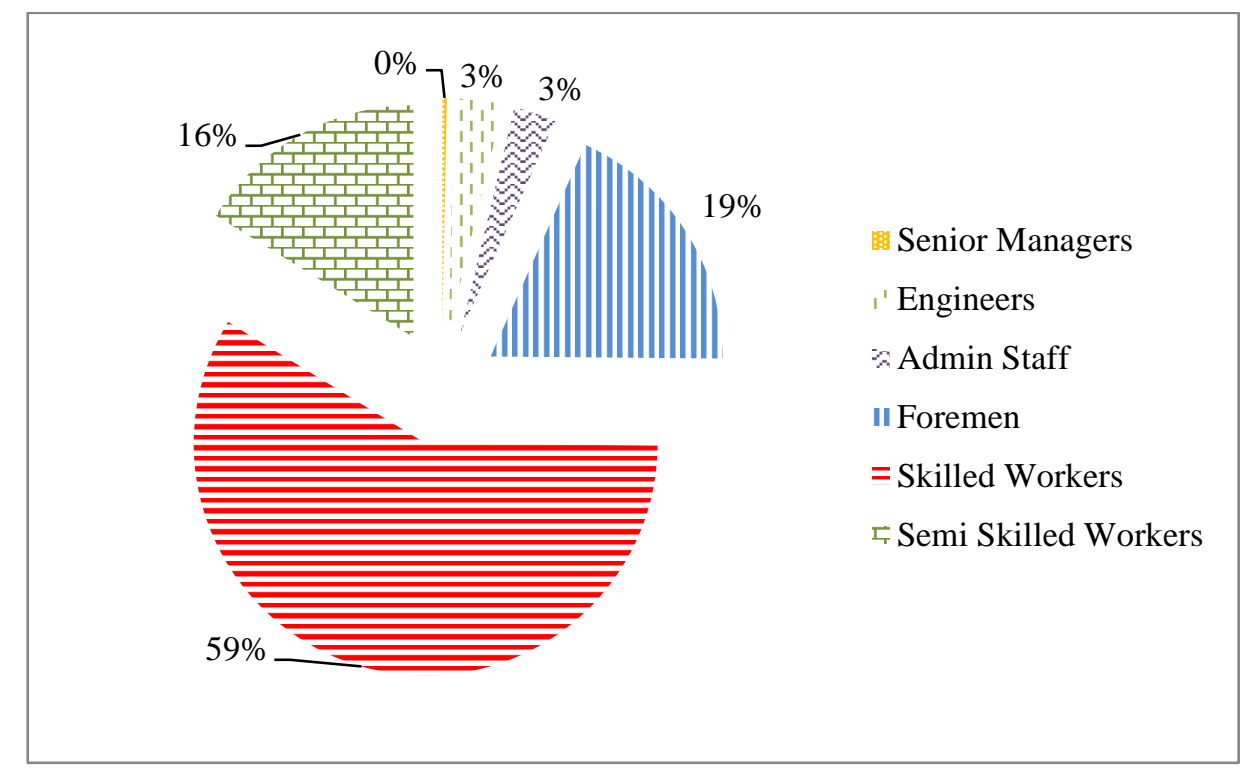

Figure 6: Distribution of foreigner workers in construction firms of Oman (OSC, 2016) 


\begin{tabular}{|l|c|c|}
\hline Sector & Establishments (000) & Workers (000) \\
\hline Construction & 65.419 & $1,702.502$ \\
\hline Trade and Repair Services & 128.633 & $1,107.119$ \\
\hline Manufacturing & 30.292 & 468.069 \\
\hline $\begin{array}{l}\text { Real Estate and Rental and Business } \\
\text { Services }\end{array}$ & 30.702 & 608.139 \\
\hline $\begin{array}{l}\text { Transportation Storage and } \\
\text { Communication }\end{array}$ & 24.145 & 355.713 \\
\hline Hotels and Restaurants & 20.087 & 238.523 \\
\hline $\begin{array}{l}\text { Community and Personal Services } \\
\text { and Other }\end{array}$ & 24.591 & 156.981 \\
\hline Educational Services and Studies & 2.155 & 89.269 \\
\hline Financial Intermediation & 2.45 & 72.846 \\
\hline Health and social work & 3.394 & 86.284 \\
\hline Others & 6.49 & 140.099 \\
\hline \multicolumn{1}{|c|}{ Total } & $\mathbf{3 3 8 . 3 5 8}$ & $\mathbf{5 , 0 2 5 . 5 4 4}$ \\
\hline
\end{tabular}

Table 2: Number of Establishments and Workforce in Different Economic Sectors of U.AE (MHRE, 2018).

Similarly, taking the example of the Kingdom of Bahrain; a small country of GCC with an area of 765.30 square kilometers. According to the Gulf Research Center, Bahrain's total population was $1,501,116$ in 2017 . The number of expatriates stood at 823,610 ; representing $55 \%$ of the total population (GRC, 2018). The total workforce in the construction industry in 2018 was 174,912 representing $12 \%$ of the total population of Bahrain (LMRA, 2018). The number of Bahraini nationals employed by the construction sector was 12,235 ; representing $8 \%$ of the total construction workforce $(174,912)$ as shown in figure 7 . In terms of employment, both the Omani and Bahraini construction industries employed more workers as compared to the UK construction industry. Moreover, the employment ratio in the Omani construction industry is 4 times higher than that of the UK industry. 


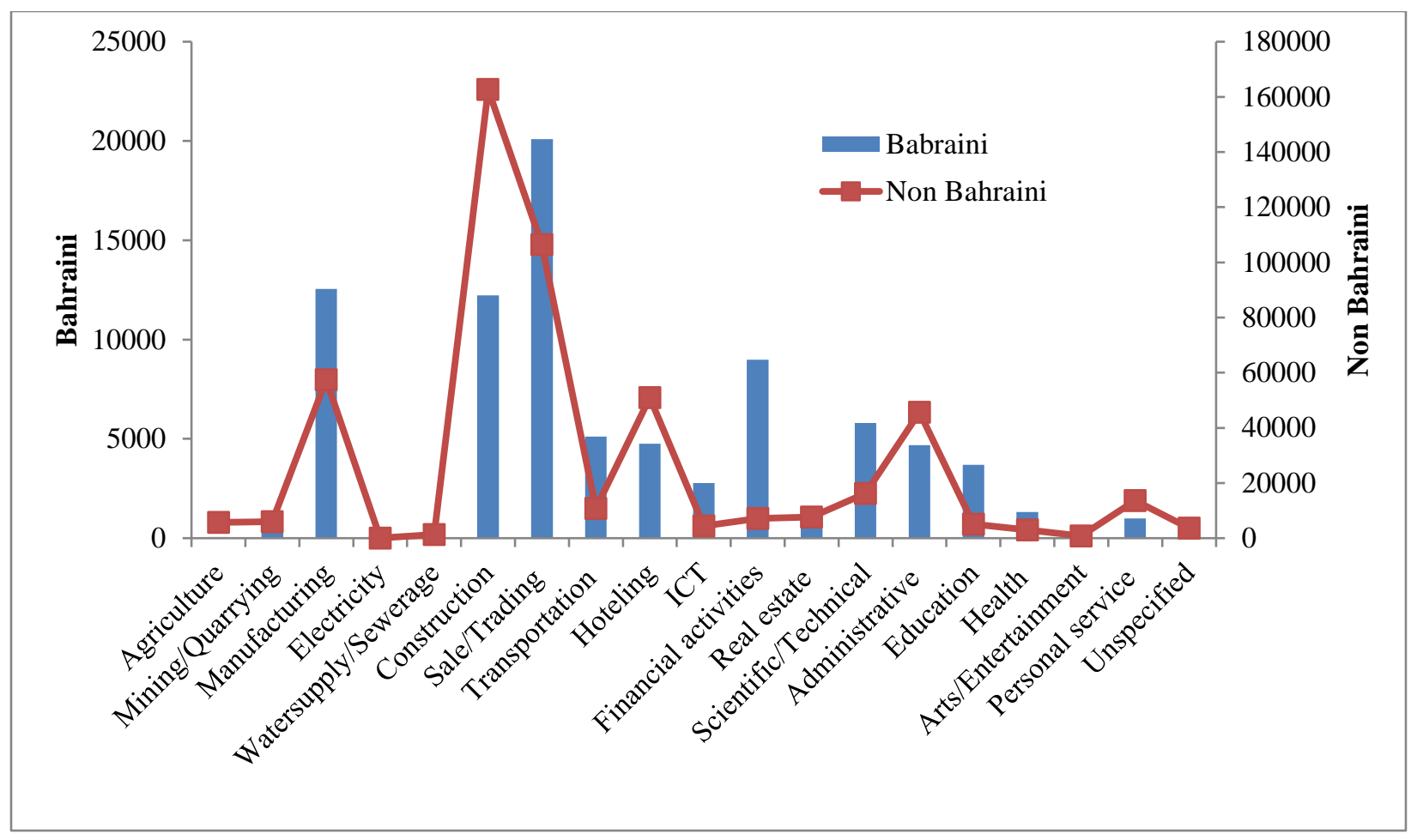

Figure 7: Employment in Different Sectors in Bahrain (LMRA, 2018)

The next section aims to provide an overview of the safety and health situation in the construction industry.

\subsection{Construction Safety and Health:}

The International Labour Organization (ILO) statistics show that approximately 2.78 million people die every year due to work-related accidents and diseases. This translates into 7,616 deaths every day worldwide. The number of injuries and sickness stands at 374 million per year, which contributes towards individual absenteeism from work for so many days. Although the human life is priceless, and cannot be translated into money, the ILO estimates the annual economic cost of the poor occupational and health practice to be $3.94 \%$ per year of the GDP (ILO, 2018). Statistics published by the Safe Work Australia show that in 2012 and 2013, workrelated injury and disease cost the Australian economy a total of AUS\$ 61.8 billion; representing 4.1\% of Australian GDP (Safe Work Australia, 2018). The forecast value of the world GDP for the year 2018 was US $\$ 87,504.57$ billion, thus the cost of poor occupational safety and health at a rate of $3.94 \%$ will be US $\$ 3,447.68$ billion per year (Statista, 2018-a). This is a huge cost, which is 20 times greater than the amount required to end the extreme poverty from the world 
which was calculated by Sachs (2015) at a rate of US \$ 175 billion per year. It is expected that the world GDP will rose to US $\$ 108,523.32$ billion in 2022 , which was US $\$ 74,535.41$ billion in 2012, reflecting a growth rate of $46 \%$ in these ten years (2012-2022). This shows that a total amount of US\$ 37,396.71 billion will be spent on matters arising from poor occupational safety and health conditions (Statista, 2018-a). Although the cost of poor occupational safety and health practices as shown in figure 8 , cannot be brought to zero, it can be minimized. If the cost of poor occupational safety and health practices is reduced by half (currently stands at $3.94 \%$ of the global GDP), then the expected saving in the coming three years (2020-2022) will be US\$ 6094.04 billion. Similarly, the global construction industry which is approximately $7 \%$ of the total global GDP, if this ratio will remain the same, the total construction GDP value will reach US $\$ 7596.63$ billion by 2022 (Deloitte, 2017). If it is assumed that cost of occupational safety and health in construction will be the same as other industries, which in reality is quite more than this $(\sim 3.94 \%)$; the cost of occupational safety and health in construction will reach to US\$ 299.31 billion by 2022 (figure 8 ). The saving in occupational safety and health cost in construction, by bringing the cost percentage which is $\sim 3.94 \%$ to half of the current value ( $\sim 1.97 \%)$, will be US\$291.58 billion in the next three years from 2020-2022. While estimating the cost of occupational safety and health, it is necessary to keep in mind that some accidents which results into disabilities and deaths cannot be accurately translated into financial losses, as the effect on the quality of life and suffering resulting from accidents can only be best understood by the individuals or their families. It is therefore important to consider that occupational safety and health are not only related to a financial factor, but there are other significant factors that have a greater impact on individuals and society. 


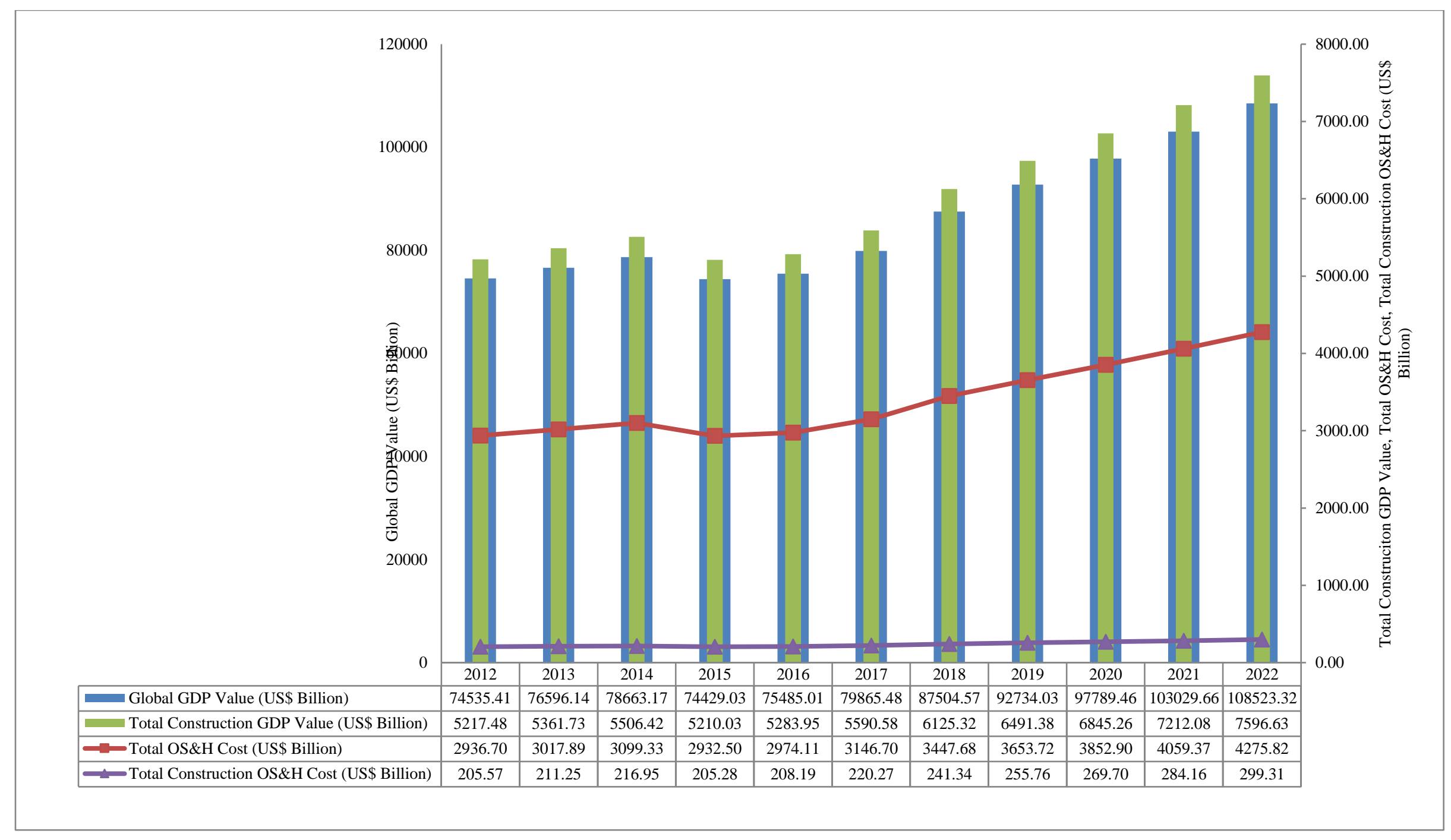

Figure 8: Global GDP and Cost of Poor Occupational Safety and Health Practices 
The construction industry is regarded as a hazardous industry. For example, the International Labour Organization data for the year 2015 reveals that every year, more than 100,000 workers die on construction sites due to different occupational safety and health (OS\&H) conditions. This means that the number of deaths on construction sites is roughly equal to 274 deaths per day. This number is nearly $30 \%$ of all occupational deadly injuries. Different studies reveal that construction workers in developed countries are three to four times more likely to die from accidents on-site compared to workers in industrial sectors. In developing countries, there is a higher risk (three to six times more) of death linked with construction work than in developed countries (ILO, 2015). Many construction workers suffer and die from work-related illnesses acquired from the prior influence of dangerous materials, such as asbestos and other chemicals. The construction industry remained at the top in most countries in terms of worker's deaths compared to other industries. For instance, statistics reveal that the construction industry in the United States involved the highest number of workers deaths in 2016, accounting for 991 deaths, with an increase of 6\% in fatalities (BLS, 2018). This number of deaths ( 991) represents $20 \%$ of all the deaths of workers in the United States. As shown in figure 9, the number of fatalities in 2016 was reduced by $25 \%$ compared to 2006. The fatalities in 2006 were 1,239. Despite this reduction, the current number of fatalities (991) is still alarming. The data further shows that 'fall from a height' was one of the main reasons for these fatal accidents, accounted for 384 deaths $(39 \%)$. 


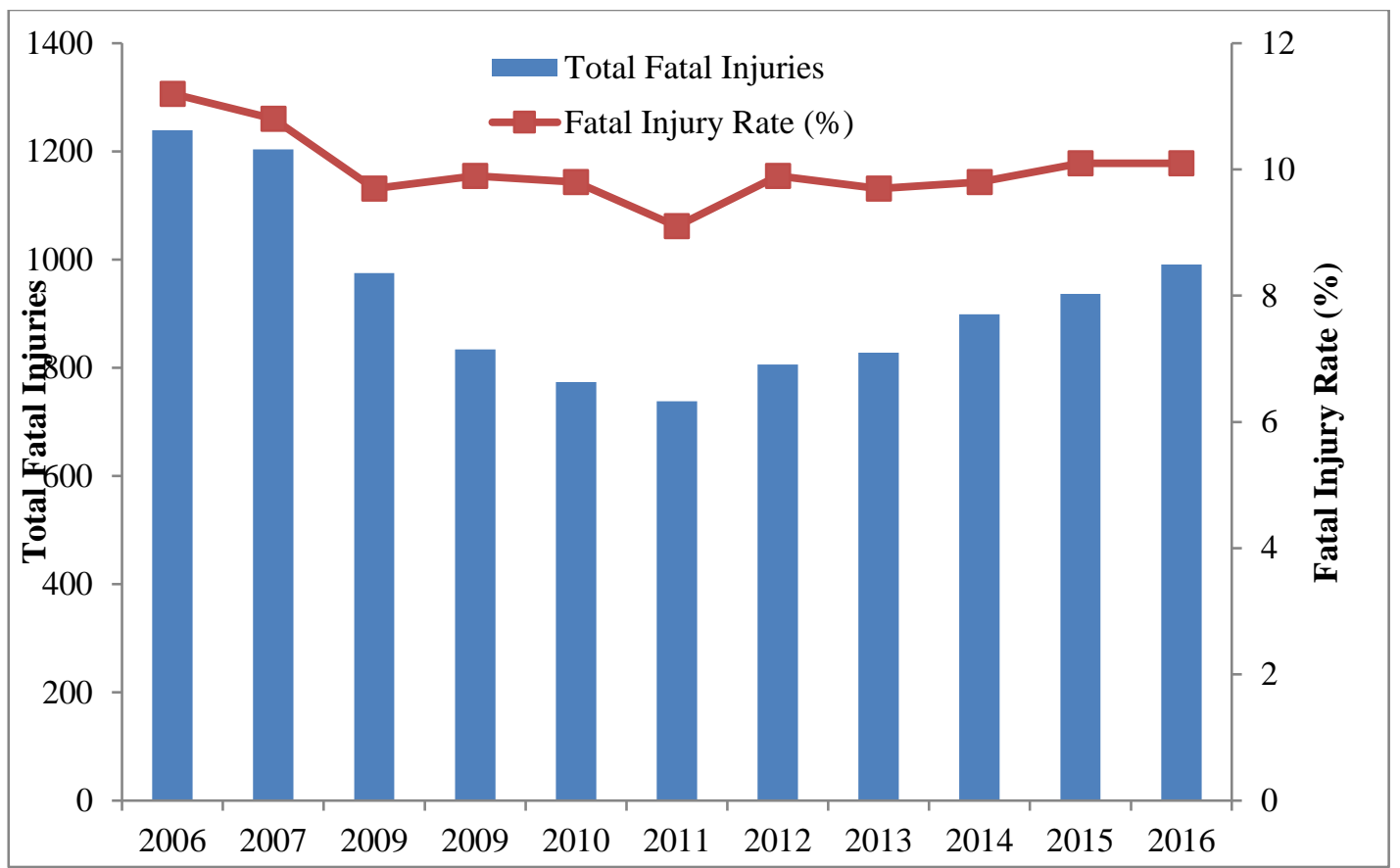

Figure 9: Construction worker fatalities and fatalities injury rate in USA-2016 (BLS, 2018).

Similarly, the statistics published by the Health and Safety Executive (HSE) in the United Kingdom show that there were 144 fatal injuries to workers in the past year, out of which 38 were from the construction sector as shown in figure 10. The main reason for the fatalities in the UK is similar to the USA, which is falls from height, accounted for 35 (24.3\%) of the total fatal accidents (HSE, 2018). The comparison of fatalities which was 233 in 2007-2008 and 144 in 2017-2018 shows that the fatality rate has been down by $62 \%$. The safety performance in the United Kingdom is, therefore, comparatively better than the United States as the reduction in fatalities was only $25 \%$ in the United States. This is a simple comparison which only considers the reduction in the number of fatalities, irrespective of the size of the industries in both countries. It is, therefore, necessary that other parameters need to be considered in such comparison. The comparison of the safety performance of one country with another country could help organizations to learn from each other's experience and to improve the safety performance in their respective jurisdictions. 


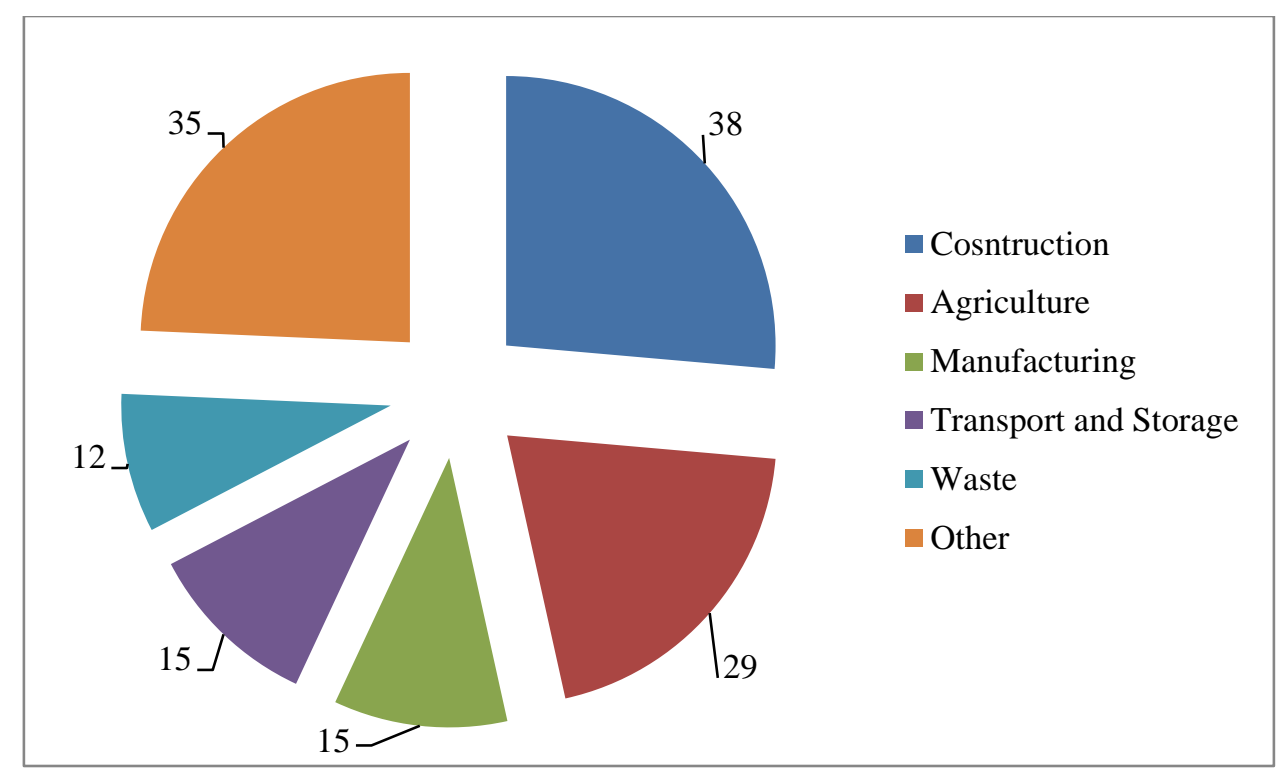

Figure 10: Occupational Fatal Injuries in UK 2017-2018 (HSE, 2018)

Similarly, in Australia, there have been 182 fatalities in 2016 representing a rate of death of 1.5 per 100,000 workers (Safe Work Australia, 2018). The number of fatalities and fatalities rate, both have been reduced in Australia since 2006, which was 284 and 2.8\% respectively as shown in figure 11. The reduction in the number of fatalities considering the 2006 and 2016 data is recorded as 56\%. The data further reveals that there were 35 fatalities among the workers working in the construction industry of Australia in 2016, representing $19 \%$ of the total fatalities. Figure 12 further shows the distribution of fatalities that took place in 2016 in the different Australian industries. The figure clearly reflects that the construction industry falls in the top three industries with the highest fatalities. Overall, the industries of Transport, postal and warehousing; Agriculture, forestry and fishing; and Construction accounted for $69 \%$ of the total fatalities and are therefore regarded as the most hazardous industries in Australia. The most common and frequent causes of fatality in the Australian construction industry is, again, the same as that of the United Kingdom and the United States, which is falls from height, accounted for $27 \%$ of all the fatalities. This percentage is based on data spanning over the ten years from 2006 to 2016. 


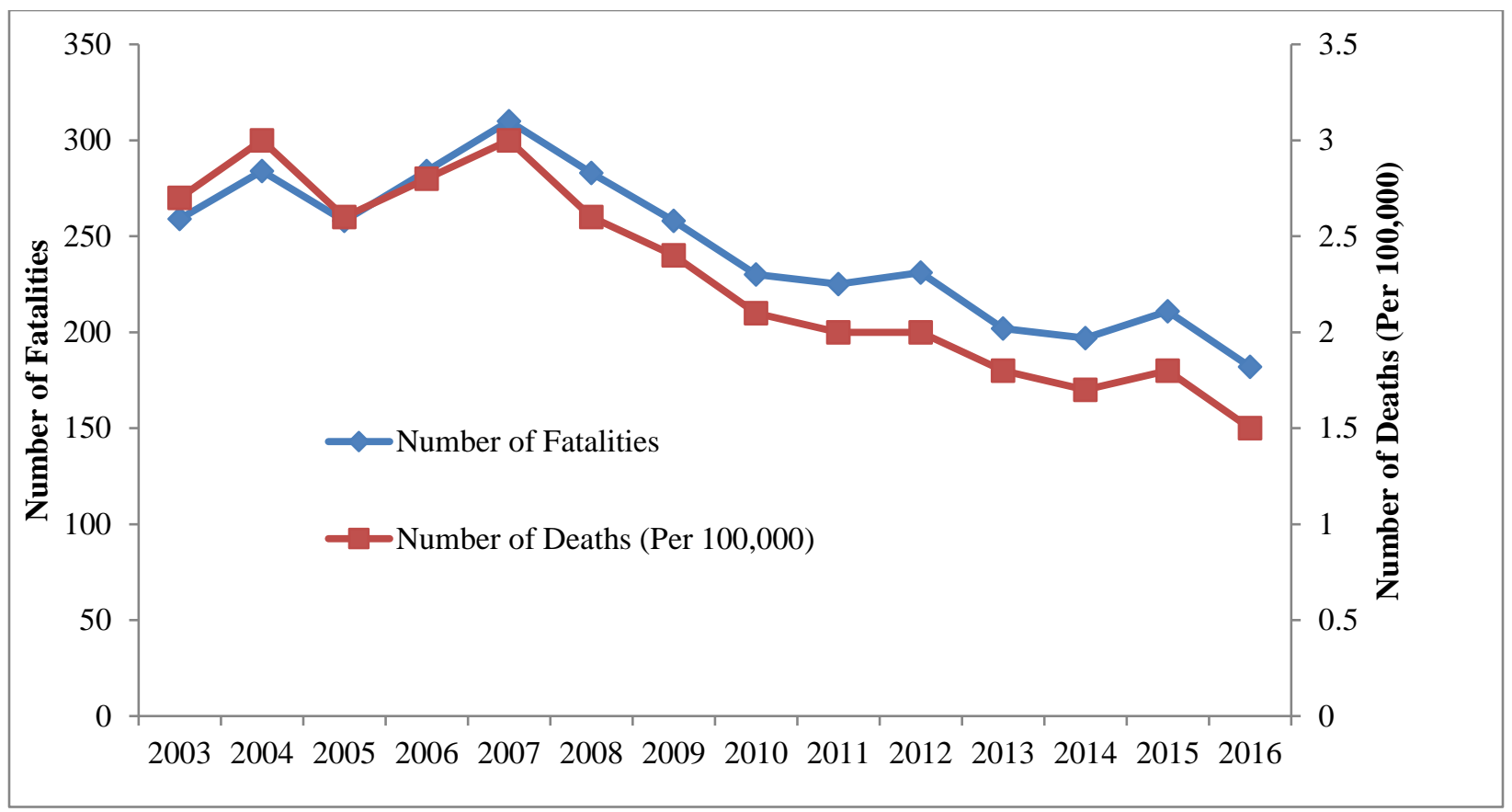

Figure 11: number of fatalities and fatality rate in Australia (2003 - 2016) - (Safe Work Australia, 2018) 


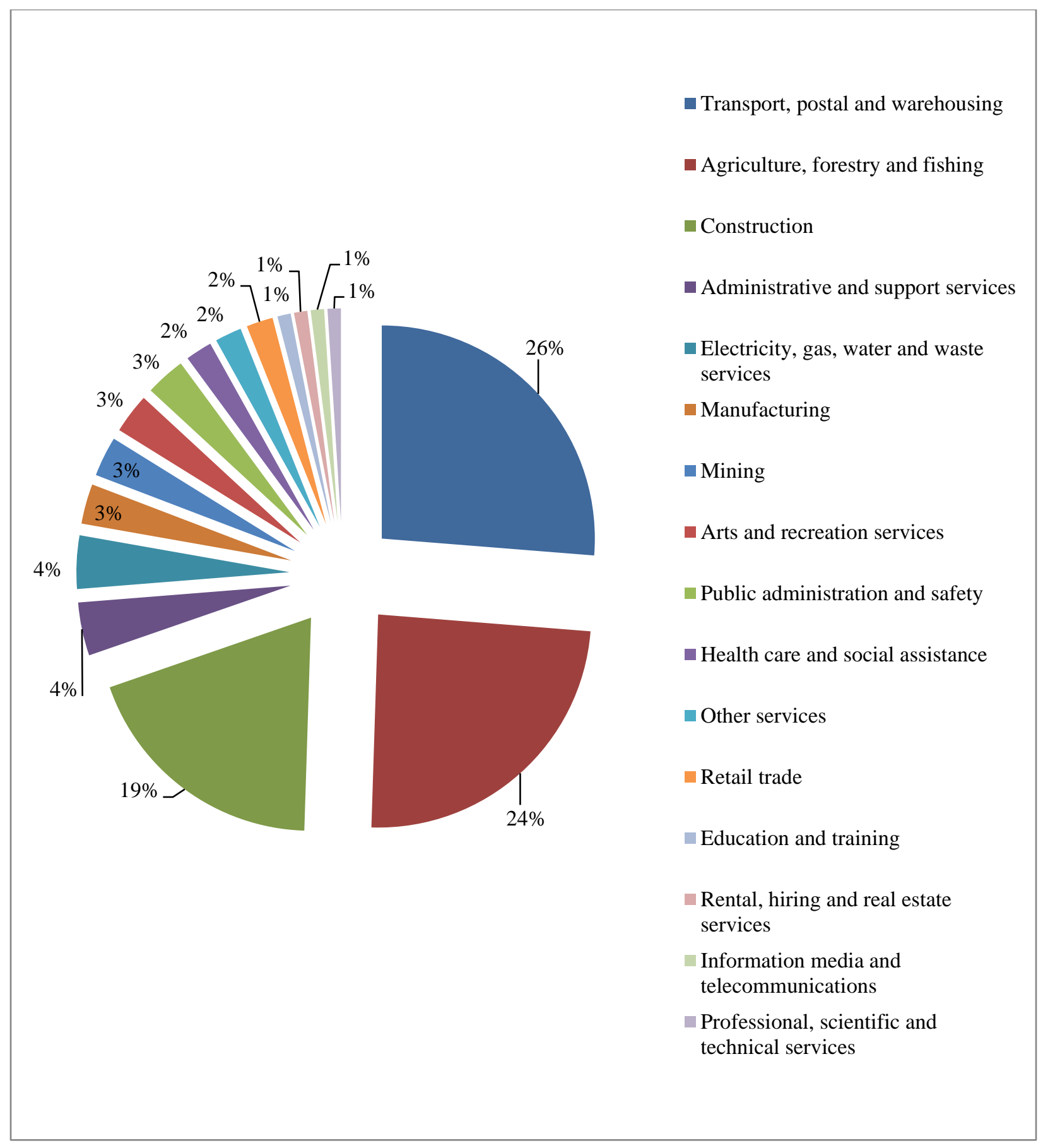

Figure 12: Distributions of Fatalities in Australian Industries (Safe Work Australia, 2018)

As the focus of this research is the GCC construction industry, the next section, therefore, aims to explore the safety and health in the GCC construction industry. 


\subsection{Construction Safety and Health in GCC Countries:}

Although it is a fact that the construction industry is not accident-free anywhere in the world, the situation in the GCC countries is particularly alarming. There is a lack of accurate data related to the number of accidents and fatalities in these countries. The most frequent source of information is the reports published by the media or international independent organizations. Recently, the deaths of construction workers in the construction of a stadium for the football world cup 2022 have attracted the attention of media and international organizations. Some of these reports show the number of construction workers that died in the project has already reached 1200. Some of the reports estimate that the number of deaths in this project will reach 4000 by the end of 2020 when it is completed (Safety Media, 2018; ITUC, 2014). The Human Rights Watch report indicates that the total workforce in Qatar is approximately two million, with $95 \%$ of this workforce being expatriates. A total of 800,000 expatriates $(40 \%$ are employed by the construction sector (Human Rights Watch, 2018). The report further shows that in only 2012, a total of 520 workers from India, Bangladesh, and Nepal died due to different work-related accidents and conditions in Qatar.

Similarly, Umar and Wamuziri (2016-b) noted that, officially, there are no statistics in Oman as to how many construction workers were injured at work. However, data from ten reputable construction organizations show that in 2014, more than 3500 construction workers received medical treatment due to work-related injuries. Due to the severity of the injuries, around $10 \%$ of these workers were hospitalized. The report further reveals that roughly $18 \%$ of these workers, who were hospitalized, later died at their work or in hospital. In comparison to the previous year's data, the number of injured workers rose by 246. For various reasons including reputation, company owners hesitate to publicize such information. Umar and Wamuziri (2016-c) further quoted the reports of one daily newspaper covering six months (from May 2015 to November 2015), which stated that 9 construction workers died and 25 were injured in Oman. Apparently, these accidents took place in the major cities of Oman, therefore were reported in the newspapers, there may have been accidents resulting in injuries and fatalities in remote areas, but these were not reported in the newspaper. Thus, the actual number of fatalities and injuries may be greater than those reported in the newspaper. 
In the United Arab Emirates, almost $70 \%$ of construction organizations have a serious lack of understanding of the importance of health and Safety policy. Construction organizations classified as medium in size, have no dedicated health and safety officer. Most of the small construction organizations and some of the medium-sized construction organizations do not have a written health and safety policy. Only $18 \%$ of construction organizations conduct continuous health and safety training of their workers (Middle East Annual Conference, 2014). Statistics related to occupational health and safety performance of construction organizations working in Dubai shows that in 2013, $71 \%$ of the construction companies (out of 130) have no occupational health and safety training for their workers. Similarly, more than $70 \%$ of the construction workers believe that the training they received was outdated (Safety Media, 2018).

The statistics published by the General Organization for Social Insurance (GOSI) of Saudi Arabia indicated that in the third quarter of 2018, occupational injuries in construction were $47 \%$ of the total occupational injuries in Saudi Arabia as shown in figure 13 (GOSI, 2018). This graph clearly shows that the construction industry in Saudi Arabia is the most hazardous sector which accumulates almost half of the injuries $(3,625$ out of 7,776$)$ that took place in the third quarter of 2018. If the number of injuries is estimated at the same rate as of the third quarter of 2018, the total number of injuries will stand at $14,500(3,625 \times 4=14,500)$. The statistics further reveal that in the same period, fall from height was the most frequent cause of injuries followed by struck and collision, then rubbed and abrasion (figure 14). The data from the General Organization for Social Insurance further indicates that the number of deaths in the same period was. This can be translated into the number of deaths per year which would roughly be equal to $64(16 \times 4=64)$. This number, however, appears not to be reliable simply because of the overall health and safety situation in the region. For instance, one project, the football world cup stadium, in Qatar resulted in 1200 death from 2010 to 2017, roughly 171 deaths per year. It is hard to believe that worker's deaths per year in the UK $(\sim 144)$ are more than the deaths of workers in Saudi Arabia ( 64). Similarly, in the United States, there are robust occupational health and safety systems that are proposed and implemented through the government organization's Occupational Safety and Health Administration (OSHA). Despite these systems, there were 991 fatalities per year $(10.10 \%$ of the total injuries) in the United States; a lot more than the fatalities in Saudi Arabia ( $\sim 64$ or $0.2 \%$ of the total injuries). The General Organization for Social Insurance, Saudi Arabia's statistics for the same period further shows that 4002 
injuries (51\%) out of 7,776 were recovered without disabilities, while 386 injuries (5\%) resulted in permanent disabilities. The report further indicates that 3,372 injuries (43\%) are still under treatment as shown in table 3.

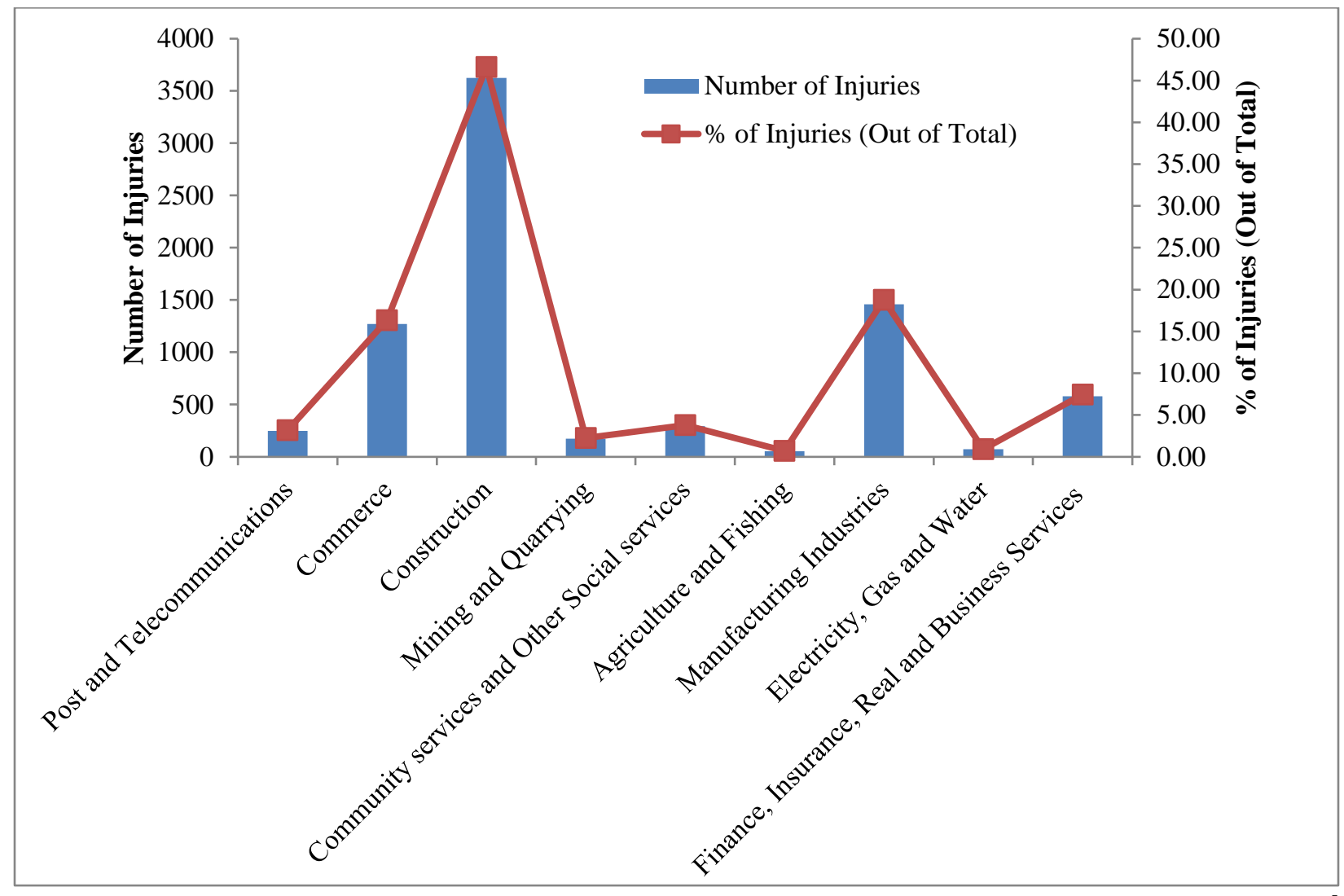

Figure 13: Number and Percentage of Injuries in Different Sectors in Saudi Arabia $-3^{\text {rd }}$ Quarter 2018 (GOSI, 2018). 


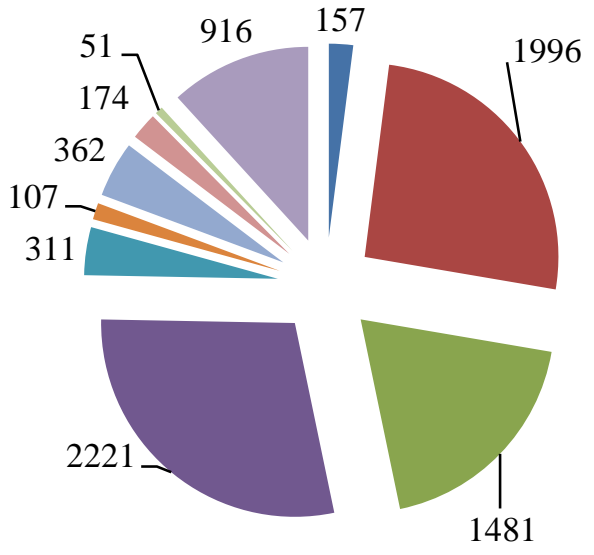

Caught In

- Struck and Collision

- Rubbed and Abrasion

- Fall from Height

- Transport and car Accidents

Excessive stress

Bodily Reaction

- Contact with Extreme Temperature

Contact with Radiation and Caustics

Other Causes

Figure 14: Different Causes of Injuries in Saudi Arabia - $3^{\text {rd }}$ Quarter 2018 (GOSI, 2018). 


\begin{tabular}{|c|c|c|c|c|}
\hline \multirow{2}{*}{$\begin{array}{c}\text { During the Third Quarter } \\
2018 \\
\text { Office name }\end{array}$} & \multicolumn{4}{|c|}{$\begin{array}{l}\text { Injuries distribution in the private sector } \\
\text { by recovery situation }\end{array}$} \\
\hline & $\begin{array}{c}\text { Cured } \\
\text { Without } \\
\text { Disability }\end{array}$ & $\begin{array}{c}\text { Cured } \\
\text { With } \\
\text { Disability }\end{array}$ & Death & $\begin{array}{l}\text { Under } \\
\text { recovery }\end{array}$ \\
\hline Riyadh Office & 864 & 182 & 7 & 612 \\
\hline Al Qassem Office & 47 & 9 & 1 & 116 \\
\hline Hail Office & 6 & 0 & 1 & 17 \\
\hline Al Kharj Office & 0 & 1 & 0 & 26 \\
\hline Makkah/Jeddah Office & 793 & 59 & 1 & 657 \\
\hline Makkah Office & 319 & 24 & 3 & 137 \\
\hline Madinah Office & 199 & 35 & 0 & 332 \\
\hline Tabouk Office & 28 & 2 & 0 & 43 \\
\hline Al Taif Office & 60 & 2 & 0 & 57 \\
\hline Yanbu Office & 29 & 11 & 0 & 45 \\
\hline Eastren Region Office & 1181 & 23 & 2 & 504 \\
\hline Ahsa Office & 197 & 7 & 1 & 188 \\
\hline Al Jouf Office & 0 & 0 & 0 & 1 \\
\hline Jubail Office & 228 & 17 & 0 & 127 \\
\hline Hafer Al-Batin Office & 0 & 0 & 0 & 8 \\
\hline Northren Borders Office & 1 & 3 & 0 & 2 \\
\hline Assir Office & 29 & 4 & 0 & 305 \\
\hline Jazan Office & 2 & 1 & 0 & 140 \\
\hline Al Baha Office & 6 & 0 & 0 & 24 \\
\hline Najran Office & 12 & 4 & 0 & 20 \\
\hline Bisha Office & 1 & 2 & 0 & 11 \\
\hline Total & 4002 & 386 & 16 & 3372 \\
\hline
\end{tabular}

Table 3: Number of Injuries and Recovery Status in the Industrial Sector of Saudi Arabia - 3rd Quarter 2018 (GOSI, 2018).

The occupational safety and health situation in Kuwait is not different from other GCC countries. Many researchers have concluded that construction in Kuwait is the most hazardous industry (Kartam and Bouz, 1998; Al-Tabtabai, 2002; Al-Kandary and Al-Waheeb, 2015). Construction accidents in Kuwait accounted for 34\% - 48\% for all injuries involving disabilities from 1994 to 1996. Similarly, during the same period, the accidents in the construction industry in Kuwait were accounted for deaths of 42\% - 62\% resulting from all injuries (Al-Kandary and Al-Waheeb, 2015). 
The above facts clearly reveal that the occupational health and safety conditions around the world are not at a satisfactory level. Workers in developing countries are more exposed to the risks of having accidents at work compared to developed countries (Umar, 2017-b). The construction industry is considered as the leading industry that provides work to many people globally. While the construction industry remains one of the most hazardous professions, it is expected to continue expanding in the future. The GCC construction industry is also expected to be growing and will employ more people in the future. Overall, in different GCC countries, the occupational health and safety conditions in construction are worse as compared to the more mature construction industries of developed countries. This is an open fact that the improvement of occupational health and safety conditions in all industrial sectors is in the best interest of the individuals, organizations, societies, and countries. The next section, therefore, sheds light on the methods which are useful to improve the safety performance of construction organizations.

\subsection{Improving Safety Performance:}

As discussed in the above sections, workers' deaths and injuries in construction are alarming, not only in the GCC countries, but this is a global issue in which a number of factors are involved. For instance, what causes an accident or an injury in construction? If the top management of the construction organizations knows this, they will be able to develop preventive strategies to avoid such causes or factors in their future projects. It is, therefore, necessary that top management of construction organizations know what exactly causes the accidents in construction. There are potential risks of accidents with the new materials being used in the construction sector and thus such materials in most cases are the cause of accidents in construction (Díaz-Soler et al., 2019). Accidents in a construction project may not happen on a daily basis, and apparently, management remains reluctant to spend on such issues that do not appear that frequently. The main component which management may be ignoring is that although the accidents may not be occurring on regular basis in their projects, however whenever an accident happens the cost of the accident may be overwhelming and greater than the cost of prevention of accident in the first place. Thus, it is important to know what the costs of accidents in construction are. Similarly, the existence of occupational health and safety regulations and its implementation in a country play a signification role in the reduction of occupational accidents. For instance, in the United States, worker's deaths rate before the establishment of the Occupational Safety and Health Administration Authority in 1970, were 38 per day, which then fell to 14 per day in 2016 
(OSHA, 2018). This reflects that the presence of the occupational health and safety regulations and its implementation bring a significant improvement in the safety performance at the country level. The Construction, Design, and Management (CDM) regulations which were first enforced in the United Kingdom in 1995 were review and amended periodically, and the current CDM regulations are the third version of the actual regulations became effective in 2015 (CDM, 2015). It is clear that the review of the existing occupational health and safety regulations on a periodic basis helps organizations to monitor the effectiveness and make necessary changes to the regulations when and where required. The benchmarking of a country's safety regulations with another country which display an improved safety performance can help the decision-maker to propose necessary amendments to the existing regulations.

One of the most important factors which contribute to the performance of workers both in terms of safety and productivity is the worker's wellbeing. Especially, when it comes to GCC countries, the hot and humid environment could significantly affect the worker's performance. There have been many studies in different parts of the world, where it has been shown that the worker's performance is directly linked with the environmental condition such humidity and temperature (Xiang et al, (2014), Yi and Chan, 2017). The researchers have also established that the human response process is highly affected by their physical health (Beevers and MacGregor, 1999; Yi and Chan, 2016). The physical health of workers can be easily assessed by their body mass index, blood pressure, and heart rate. There is, however, no comprehensive study in this area in any GCC country which considers these factors, despite the fact that all GCC countries are well known for their hot and humid climatic conditions. For instance, the Qatar Meteorology Department data shows that the mean air temperature in Doha in the month of July remains as $35.4^{\circ} \mathrm{C}$, while the mean relative humidity in the same month stands at $49 \%$. Similarly, the highest temperature recorded in 2010, in Doha was 50.4 ${ }^{\circ} \mathrm{C}$ (Meteorology Department, 2018). The official data in Oman shows that the average maximum temperature in summer in Oman reaches $40^{\circ} \mathrm{C}$ as shown in figure 15 (DGM, 2018). The maximum temperature in Oman reported by different newspapers was higher than the one reported by official authorities. A news article published in a daily newspaper in 2017 , reported the maximum temperature in Oman was $50^{\circ} \mathrm{C}$. (MD, 2016). Similarly, another daily newspaper reported that the maximum temperature recorded in Oman in 2015 was $48^{\circ} \mathrm{C}$ (TOM, 2015). These high temperatures recorded in the GCC countries reflect that the effect of heat stress on construction worker's performance appears 
to be more if compared to any other part of the world. Similarly, the worker's body pain supplemented by the extensive temperature may have an impact on their response process and could affect their safety and productivity. During the construction process, workers are required to work in an awkward position for a long time. This may significantly contribute to body pain in specific areas.

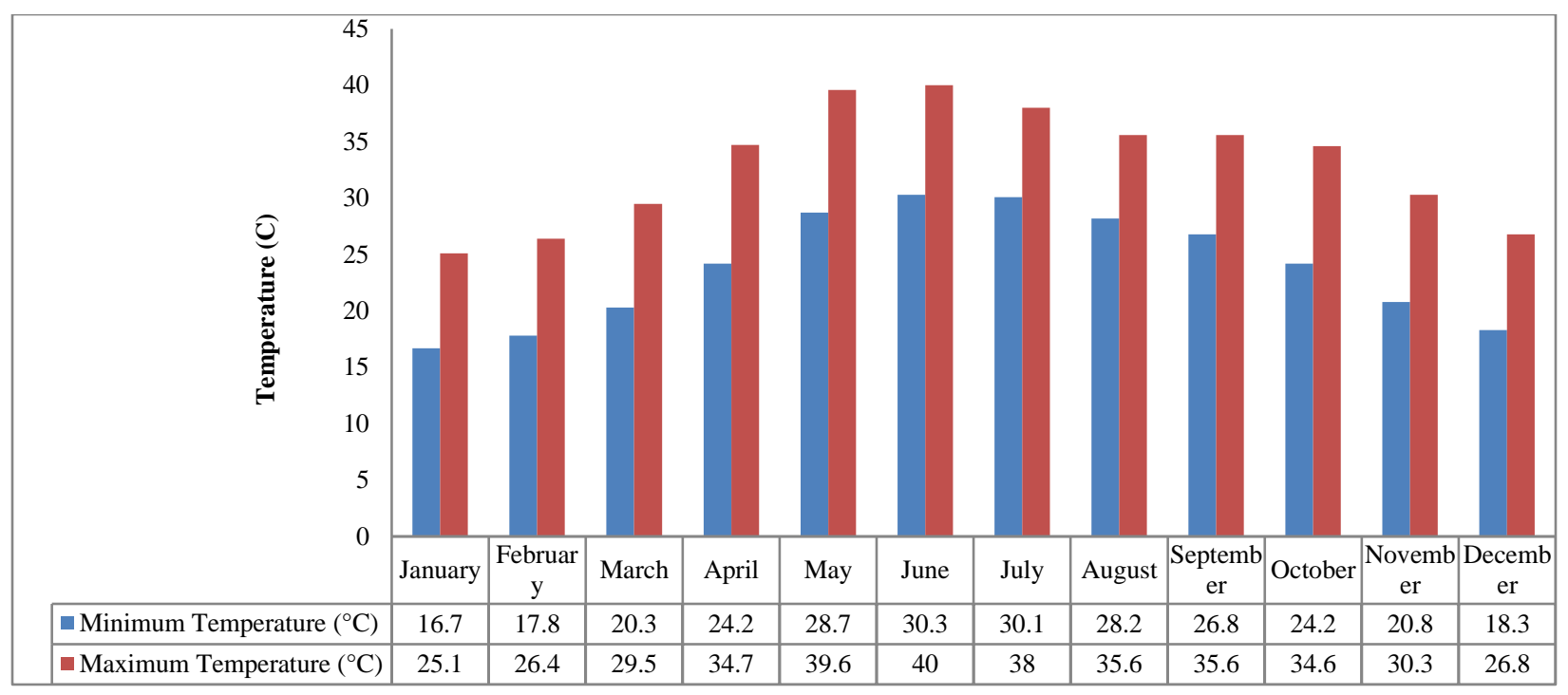

Figure 15: Average Minimum and Maximum Temperature in Oman (DGM, 2018)

While there have been several concepts and methods to improve safety performance and avoid accidents in the construction sites, safety culture and safety climate have attracted many researchers and practitioners worldwide due to its significant impact on safety improvement (Kines et al., 2011; Umar and Wamuziri, 2017; Probst et al., 2019). The concepts of safety culture and safety climate got more appreciation since 1980 when the theories of human age factors were adopted in organization performance. The safety culture represents the overall culture of an organization reflecting how the safety is considered or treated in that organization. For example, if safety negligence in an organization is a routine practice, the organization will reflect poor safety culture. Such a culture could naturally result in accidents. On the other hand, if in an organization, health and safety regulations are strictly followed by the management and employers, such organization will display a rich safety culture and the number of accidents will be comparatively lower than the organization with a poor safety culture. Overall, safety culture is contributed by the workers; however, it is highly influenced by the organization's top 
management. Some researchers, however, stress that safety is highly influenced by the worker's behaviors and thus considers that monitoring of such behavior is important to ensure a rich safety culture at the workplace (Lee et al., 2019).

The researchers defined the safety climate as a subset of organizational climate which is based on the worker's or employees' perceptions. The assessment of safety climate is considered as a barometer of safety culture. Therefore, a mature safety climate will reflect a rich safety culture (Zohar, 2002). The results of the safety climate can be regarded more effective as it informs the management very clearly in which areas the organization needs improvement to achieve the required level of maturity (Kines et al, 2011). Worldwide, many tools have been developed for the assessment of safety climate which was used in different industries including construction. Although, there is no such tool developed or used in the GCC countries. The construction industry in the GCC region has its own parameters. For instance, the workforce, which is more than $90 \%$ expatriates, belongs to different South Asian countries. A tool developed and used in the United Kingdom or United States may not be effective to be adopted in the GCC countries due to a variety of factors pertaining to the industry itself. This clearly reflects that there could be a gap in understanding the safety climate factors which may have a high influence on the safety climate in the GCC countries.

The results and discussion of the semi-structured interview are provided in the next section.

\subsection{Results and Discussion of Semi-Structure Interview:}

The above discussion shows that there is potential for research in the areas of occupational safety and health in construction not only in the GCC countries but worldwide. The themes of such research may include the causes of accidents; the costs of accidents; the heat stress; the occupational health and safety regulations; worker's wellbeing and health; and the safety climate. To confirm the above key areas for research which could lead the construction organizations to improve their safety and health performance, a total of 12 interviews with the main stakeholders across the GCC countries were conducted. An approach of semi-structured interviews explained by Umar and Egbu (2018-b) was considered to be best suited in this situation. All the interviewees agreed that much need to be done to improve the occupational safety and health in the region. The key areas for research that could improve the safety and health in the GCC construction reported by the interviewees include the following components: 
a) Causes of accidents: Construction organizations should properly evaluate the causes of accidents to effectively make preventive strategies to avoid such accidents in their future projects.

b) Costs of accidents: Construction organizations in the region should have a better understanding of the costs of accidents and the costs of accidents prevention.

c) Heat stress: Construction Managers in construction organizations should effectively protect their workers from heat stress.

d) Occupational safety and health regulations: Both the workers and construction organizations should be aware of occupational safety and health regulations. Occupational safety and health regulations should be carefully reviewed periodically.

e) Worker wellbeing: Worker wellbeing should be one of the main priorities of construction organizations.

f) Safety culture and safety climate: Construction organizations should adopt the safety culture and safety climate approach to improve their safety performance more effectively.

\section{Conclusion:}

The construction industry is one of the important industries which play a key role in the development of countries and providing jobs to a huge number of workers around the world. The construction industry is further expected to be growing rapidly in the future due to increasing population and urbanization. As the construction industry grows, the risk factors associated with the industry will also grow. One of the identified risks associated with construction is occupational fatalities and injuries. In this paper, an attempt is made to highlight this risk by exploring occupational safety and health in construction industry. The data from different sources show that the construction industry is one of the main hazardous industries in which the number of fatalities and injuries is alarming. A brief comparison of GCC countries' safety performance is made with some of the advanced countries which display an improved safety performance. The statistics presented in this paper show although construction is a leading industry in all GCC countries, occupational safety and health performance in all these countries is not only low but also alarming. The number of deaths in one of the major construction projects 
in a GCC country stood at 1200 deaths and is expected to reach 4,000 by the end of 2020 when the project will be completed. This is one of the major projects in the region for hosting one of the world-famous events, attracting the focus of all national and international organizations, but still the numbers of fatalities are overwhelming. The status of occupational safety and health in small projects could be worse particularly if such project doesn't get the attention of national or international organizations. The discussion made in this paper suggests that the construction industry is growing not only in GCC but worldwide. It strengthens the argument that the growth of the industry will also increase the concern associated with the safety of construction workers. The GCC construction industry and its safety performance are particularly discussed. The construction industry in GCC has its own context and parameters related to geographic conditions and workforce. An attempt is made to highlight the key areas which could lead the GCC construction towards an improved safety performance. These key areas were initially identified from the existing literature and then confirmed through interviews held with the selected respondents from academic and industry. The key areas found in this research are;
a) Causes of accidents
b) Costs of accidents
c) Heat stress
d) Occupational safety and health regulations
e) Worker wellbeing
f) Safety culture and safety climate

All the respondents agreed that there is a need for research in these areas in order to better understand its implications on safety output. Further research is therefore recommended in the above-suggested areas to ascertain its effects on safety performance in GCC construction. 


\section{References:}

AB (Arabian Business) (2017) GCC construction market worth $\$ 2 \cdot 4$ trn, has 22,000 active projects. Arabian Business, 16 September. See http://www.arabianbusiness.com/industries/construction/378423-wkdgcc-constructionmarket-worth-24trn-has-22000-active-projects. (accessed 29/01/2018).

ABS (Australian Bureau of Statistics). 2018. Population Size and Growth. Australian Bureau of Statistics, Canberra, Australia. See: http://www.abs.gov.au/Population. (accessed 19/11/2018).

Al-Kandary, N. and Al-Waheeb, S., 2015. Patterns of accidental deaths in Kuwait: a retrospective descriptive study from 2003-2009. BMC public health, 15(1), p.302. https://doi.org/10.1186/s12889-015-1630-8.

Al-Tabtabai, H.M., 2002. Analyzing construction site accidents in Kuwait. Kuwait J. Sci. Eng, 29(2), pp.213-238.

Beevers, D.G.; MacGregor, G.A. Hypertension in Practice, 3rd ed.; CRC Press: Boca Raton, FL, USA, 1999.

Beven, R. (2010). Global Construction 2020 and Global Opportunities. Pinsent Masons, London UK. See: http://www.tecniberia.es/documentos/GlobalConstruction2020andGlobalOpportunities.p df (accessed 17/11/2018).

BLS (Bureau of Labour Statistics). 2018. Census of Fatal Occupational Injuries (CFOI) - Current and Revised Data, Bureau of Labour Statistics, United States Department of Labour, Washington D.C. USA. See: https://www.bls.gov/iif/oshcfoi1.htm\#2016 (accessed 22/11/2018).

CDM (Construction Design and Management). 2015. Managing health and safety in construction. Construction (Design and Management) Regulations 2015. Guidance on Regulations, Health and Safety Executive (HSE), London, UK. See: http://www.hse.gov.uk/pubns/books/1153.htm. (accessed 01/12/2018).

Census Bureau, 2018. Value of Construction Put in Place at a Glance, September 2018. United States Census Bureau, Washington, USA. See: https://www.census.gov/construction/c30/c30index.html. (accessed 19/11/2018).

Deloitte (2015) Deloitte GCC Powers of Construction 2015 Construction - The Economic Barometer for the Region. Deloitte, Dubai, United Arab Emirates. See: http://businesshumanrights.org/sites/default/files/documents/Deloitte-GCC-Powers-of-Construction2015.pdf (accessed 29/03/2018).

Deloitte, 2017. Deloitte GCC Powers of Construction 2017, If it's fundable it's feasible. Deloitte, Dubai, United Arab Emirates. See: https://www2.deloitte.com/content/dam/Deloitte/xe/Documents/realestate/construction/gc cpowersofconstruction/me_construction_gccpoc2017.pdf. (accessed 27/11/2018). 
DGM (Directorate General of Meteorology) (2018) Average Temperature. Directorate General of Meteorology, Muscat, Oman. See:

http://www.met.gov.om/opencms/export/sites/default/dgman/en/weather-chart/historicaldata/ (accessed 21/03/2018).

Díaz-Soler, B.M., Martínez-Aires, M.D. and López-Alonso, M., 2019. Potential risks posed by the use of nano-enabled construction products: A perspective from coordinators for safety and health matters. Journal of Cleaner Production, 220, pp.33-44. https://doi.org/10.1016/j.jclepro.2019.02.056.

EUCS (European Union Construction Sector). 2016. Brochure - The European construction sector - A global partner - 2016 edition. European Union, Brussels, Belgium. See: http://ec.europa.eu/DocsRoom/documents/15866/attachments/1/translations. (accessed 17/11/2018).

GCC Stat (2018) Data Base for Population: Statistical Centre for the Cooperation Council for the Arab Countries of the Gulf (GCC STAT). GCC Stat, Muscat, Oman. See: http://dp.gccstat.org/en/DataAnalysis?BLusCmXUaW2gz3lqQNA (accessed 29/01/2018).

GOSI (General Organization for Social Insurance). 2018. Open Data Library. General Organization for Social Insurance, Riyadh, Saudi Arabia. See: https://www.gosi.gov.sa/GOSIOnline/Open_Data_Library\&locale=en_US. (accessed 24/11/2018).

GRC (Gulf Research Center). 2018. Bahrain Population by Nationalities. Gulf Research Center, Geneva, Switzerland. See: http://gulfmigration.org/bahrain-population-nationalitybahraini-non-bahraini-sex-age-groups-2017/. (accessed 18/11/2018).

HSE (Health and Safety Executive). 2018. Workplace fatal injuries in Great Britain 2018. Health and Safety Executive, London, UK. See: http://www.hse.gov.uk/statistics/pdf/fatalinjuries.pdf. (accessed 22/11/2018).

Human Right Watch, 2018. Qatar: Take Urgent Action to Protect Construction Workers. Human Right Watch, New York, USA. See: https:/www.hrw.org/news/2017/09/27/qatar-takeurgent-action-protect-construction-workers. (accessed 24/11/2018).

ILO (International Labour Organization) (2015) Construction: A Hazardous Work. ILO, Geneva, Switzerland. See http://www.ilo.org/safework/areasofwork/hazardouswork/WCMS 356576/lang-en/index.htm. (accessed 11/03/2017).

ILO (International Labour Organization). 2018. Safety and health at work. International Labour Organization, Geneva, Switzerland. See: https://www.ilo.org/global/topics/safety-andhealth-at-work/lang--en/index.htm. (accessed 19/11/2018).

ITUC (International Trade Union Confederation). 2014. The Case Against Qatar, Host of the FIFA 2022 World Cup, ITUC Special Report, March 2014. International Trade Union Confederation, Brussels, Belgium. See: https://www.ituccsi.org/IMG/pdf/the_case_against_qatar_en_web170314.pdf. (accessed 26/11/2018).

Kartam, N.A. and Bouz, R.G., 1998. Fatalities and injuries in the Kuwaiti construction industry. Accident analysis \& prevention, 30(6), pp.805-814. https://doi.org/10.1016/S00014575(98)00033-5. 
Kines, P., Lappalainen, J., Mikkelsen, K.L., Olsen, E., Pousette, A., Tharaldsen, J., Tómasson, K. and Törner, M., 2011. Nordic Safety Climate Questionnaire (NOSACQ-50): A new tool for diagnosing occupational safety climate. International Journal of Industrial Ergonomics, 41(6), pp.634-646.

Lee, P.C., Wei, J., Ting, H.I., Lo, T.P., Long, D. and Chang, L.M., 2019. Dynamic Analysis of Construction Safety Risk and Visual Tracking of Key Factors based on Behavior-based Safety and Building Information Modeling. KSCE Journal of Civil Engineering, pp.1-13. https://doi.org/10.1007/s12205-019-0283-Z.

Li, R.Y.M. and Poon, S.W., 2013. Using Web 2.0 to share the knowledge of construction safety as a public good in nature among researchers: The fable of economic animals. In Construction Safety (pp. 81-95). Springer, Berlin, Heidelberg. https://doi.org/10.1007/978-3-642-35046-7.

Li, R.Y.M., Chau, K.W. and Zeng, F.F., 2019. Ranking of Risks for Existing and New Building Works. Sustainability, 11(10), p.2863. https://doi.org/10.3390/su11102863.

LMRA (Labour Market Regulatory Authority), 2018. Bahrain Labour Market Indicators, Labour Market Regulatory Authority, Bahrain. See: http://blmi.lmra.bh/2010/12/mi_data.xml (accessed 18/11/2018).

MD (Muscat Daily) (2016) 2016 Was Hottest Year on Record. Muscat Daily, 22 January. See: http://www.muscatdaily.com/Archive/Oman/2016-was-hottest-year-on-record-WMO$\underline{4 \mathrm{xdr}}$ (accessed 19/11/2017).

Meteorology Department, 2018. Climate Information for Doha. Meteorology Department, Doha, Qatar. See: https://qweather.gov.qa/ClimateInfo.aspx. (accessed 29/11/2018).

MHRE (Ministry of Human Resources and Emiratizations). 2018. Open Data. Ministry of Human Resources and Emiratizations. Dubai, United Arab Emirates. See: http://www.mohre.gov.ae/en/data-library/statistical-report.aspx. (accessed 18/11/2018).

Middle East Annual Conference, 2014. Managing liability for worksite accidents. Jeremie Witt \& Antonia Birt, Associates Freshfields Bruckhaus Deringer LLP, London, UK. See: https://www.iosh.co.uk/Key-IOSH-events/Middle-East-Annual-Conference-and-AGM2014/Middle-East-Conference-presentations.aspx. (accessed 24/11/2018).

Moher, D., Liberati, A., Tetzlaff, J. and Altman, D.G., 2009. Preferred reporting items for systematic reviews and meta-analyses: the PRISMA statement. Annals of internal medicine, 151(4), pp.264-269. https://doi.org/10.1371/journal.pmed.1000097.

NCSI (National Centre for Statistics and Information). 2017. Monthly Statistical Bulletin, January, 2017. National Centre for Statistics and Information, Muscat, Oman.

NCSI (National Centre for Statistics and Information). 2017-b. Monthly Statistical Bulletin. NCSI, Muscat, Oman.

ONS (Office for National Statistics) (2017) Construction Statistics: Number 18, 2017 Edition. Office for National Statistics, London, UK. See: https://www.ons.gov.uk/businessindustryandtrade/constructionindustry/articles/constructi onstatistics/number182017edition. (accessed 01/02/2018). 
OSC (Oman Society of Contractors). 2016. Annual General Meeting: Distribution of Expatriate in Construction Organizations of Oman. OSC, Muscat, Oman.

OSHA (Occupational Safety and health Administration). 2018. OSHA is Making a Difference. Occupational Safety and health Administration, Washington, United States. See: https://www.osha.gov/oshstats/commonstats.html. (accessed 29/11/2018).

Parliament of Australia, 2018. Employment by industry statistics: a quick guide. See: https://www.aph.gov.au/About_Parliament/Parliamentary_Departments/Parliamentary_Li brary/pubs/rp/rp1718/Quick_Guides/EmployIndustry. (accessed 19/11/2018).

PC (Population Clock). 2018. Population Clock of Oman, National Center of Statistic and Information, Muscat, Oman. See: https://www.ncsi.gov.om/Pages/NCSI.aspx. See: (accessed 18/11/2018).

Probst, T.M., Goldenhar, L.M., Byrd, J.L. and Betit, E., 2019. The safety climate assessment tool (s-cat): A rubric-based approach to measuring construction safety climate. Journal of Safety Research, 69, pp.43-51. https://doi.org/10.1016/j.jsr.2019.02.004.

Sachs, J.D., 2015. The end of poverty: economic possibilities for our time. Penguin Group, New York, USA.

Safe Work Australia, 2018. Work-related traumatic injury fatalities. Safe Work Australia, Canberra, Australia. See: https://www.safeworkaustralia.gov.au/statistics-andresearch/statistics/fatalities/fatality-statistics. (accessed 22/11/2018).

Safety Media, 2018. Key Middle East Safety Statistics. Safety Media, Denbighshire, UK. See: https://safetymedia.co.uk/me/middle-east-safety-statistics/. (accessed 24/11/2018).

SHJ (Statistical Handbook of Japan) (2017) Manufacturing and Construction. Statistical Handbook of Japan, 2017. Statistics Bureau, Ministry of Internal Affairs and Communication, Tokyo, Japan. See: http://www.stat.go.jp/english/data/handbook/pdf/2017all.pdf. (accessed 01/02/2018).

Statista, 2017. Construction industry spending worldwide from 2014 to 2025 (in trillion U.S. dollars). Statista, Inc. New York, USA. See: https://www.statista.com/statistics/788128/construction-spending-worldwide/ (accessed 24/04/2018).

Statista, 2018. Construction Industry in the UK - Statistics \& Facts. Statista, Inc. New York, United States. See: https://www.statista.com/topics/3797/construction-industry-in-theuk/. (accessed 18/11/2018).

Statista, 2018-a. Global GDP (gross domestic product) at current prices. Statista, Inc. New York, USA. See: https://www.statista.com/statistics/268750/global-gross-domestic-productgdp/. (accessed 19/11/2018).

TOM (2017) Oman budget: Despite austerity, Oman committed to investment. Time of Oman, 2 January. See: http://timesofoman.com/article/99741/Oman/Government/Oman-budget:Despiteausterity-Oman-committed-to-investment (accessed 19/01/2017). 
TOM (Times of Oman) (2015) Oman weather: Sultanate likely to record hottest day in the region. Time of Oman, 10 August. See:

http://timesofoman.com/article/65283/Oman/Environment/Oman-weather:Sultanatelikely-to-record-hottest-day-in-the-region (accessed 19/11/2017).

Umar T (2016). Cost of accidents in the construction industry of Oman. Proceedings of the Institution of Civil Engineers - Municipal Engineer 170(2): 68-73, https://doi.org/10.1680/jmuen.16.00032.

Umar T and Wamuziri SC (2016-b) A review of construction safety, challenges and opportunities - Oman perspective. In Proceedings of 5th World Construction Symposium 2016 (Sandanayake YG, Karunasena GI and Ramachandra T (eds)). University of Moratuwa, Colombo, Sri Lanka, pp. 14-22.

Umar, T. and Egbu, C., 2018. Heat stress, a hidden cause of accidents in construction. Proceedings of the Institution of Civil Engineers-Municipal Engineer (pp. 1-12). Thomas Telford Ltd. https://doi.org/10.1680/jmuen.18.00004.

Umar, T. and Egbu, C., 2018-a. Causes of construction accidents in Oman. Middle East Journal of Management, 5(1), pp.21-33.

Umar, T. and Egbu, C., 2018-b. Perceptions on safety climate: a case study in the Omani construction industry. Proceedings of the Institution of Civil Engineers-Management, Procurement and Law, 171(6), pp.251-263. https://doi.org/10.1680/jmapl.18.00001.

Umar, T. and Wamuziri, S., 2016-a. Briefing: Conventional, wind and solar energy resources in Oman. Proceedings of the Institution of Civil Engineers-Energy, 169(4), pp.143-147. https://doi.org/10.1680/jener.16.00011.

Umar, T. and Wamuziri, S., 2017. Briefing: Using 'safety climate factors' to improve construction safety. Proceedings of the Institution of Civil Engineers-Municipal Engineer (Vol. 170, No. 2, pp. 65-67). Thomas Telford Ltd. https://doi.org/10.1680/jmuen.16.00020.

Umar, T. and Wamuziri, S.C., 2016-c. Using Safety Climate as A Tool for Improvement of Safety Performance in Construction Organizations. In Proceedings of 5th World Construction Symposium 2016 (Sandanayake YG, Karunasena GI and Ramachandra T (eds)). University of Moratuwa, Colombo, Sri Lanka, pp. 545-554. ISSN: 2362-0919. See: http://dl.lib.mrt.ac.lk/handle/123/11910 (accessed 15/01/2019).

Umar, T., (2019). Improving Safety Performance in the Construction Industry in Oman. PhD thesis. London South Bank University, London, UK.

Umar, T., 2017-a. Geothermal energy resources in Oman. Proceedings of the Institution of Civil Engineers-Energy, 171(1), pp.37-43. https://doi.org/10.1680/jener.17.00001.

Umar, T., 2017-b. Briefing: Defining safety leadership in construction. Proceedings of the Institution of Civil Engineers-Municipal Engineer (Vol. 170, No. 1, pp. 3-5). Thomas Telford Ltd. https://doi.org/10.1680/jmuen.16.00004.

Umar, T., 2018. Causes of delay in construction projects in Oman. Middle East Journal of Management, 5(2), pp.121-136. https://dx.doi.org/10.1504/MEJM.2018.091132. 
Umar, T., Egbu, C., \& Saidani, M. (2019-c). A Modified Method for Los Angeles Abrasion Test. Iranian Journal of Science and Technology, Transactions of Civil Engineering. https://doi.org/10.1007/s40996-019-00268-w.

Umar, T., Egbu, C., Honnurvali, M.S., Saidani, M. and Al-Bayati, A.J., 2019-a. Briefing: Status of occupational safety and health in GCC construction. Proceedings of the Institution of Civil Engineers-Management, Procurement and Law. 172(4), pp. 137-141. https://doi.org/10.1680/jmapl.18.00053.

Umar, T., Egbu, C., Honnurvali, M.S., Saidani, M. and Al-Mutairi, M., 2018-a. An assessment of health profile and body pain among construction workers. Proceedings of the Institution of Civil Engineers-Municipal Engineer. Pp. 1-12. https://doi.org/10.1680/jmuen.18.00019.

Umar, T., Egbu, C., Ofori, G., Honnurvali, M.S., Saidani, M., and Opoku., A., 2019-b. Exploring Safety Climate in Construction. International Journal of Applied Management Science, Inderscience Publisher. https://doi.org/10.1504/IJAMS.2019. 253274.

Umar, T., Egbu, C., Wamuziri, S. and Honnurvali, M.S., 2018. Occupational Safety and Health Regulations in Oman. Proceedings of the Institution of Civil Engineers-Management, Procurement and Law. 171(3): 93-99. https://doi.org/10.1680/jmapl.18.00007.

Ventures, 2018. US\$ 29.4 Bn worth of contracts awarded in GCC in Q1, 2018. Ventures Onsite, Ventures Middle East DMCC; Dubai, United Arab Emirates. See: http://venturesmiddleeast71550.activehosted.com/index.php?action=social\&chash=1c383 cd30b7c298ab50293adfecb7b18.70 (accessed 25/04/2018).

WHO (World Health Organization). 2017. 2.1 billion people lack safe drinking water at home, more than twice as many lack safe sanitation. World Health Organization, See: http://www.who.int/news-room/detail/12-07-2017-2-1-billion-people-lack-safe-drinkingwater-at-home-more-than-twice-as-many-lack-safe-sanitation. (accessed 17/11/2018).

WRI (World Resources Institute). 2017. 1.2 Billion People Living in Cities Lack Access to Affordable and Secure Housing. World Resources Institute, Washington, D.C., USA. See: https://www.wri.org/news/2017/07/release-12-billion-people-living-cities-lackaccess-affordable-and-secure-housing (accessed 17/11/2018).

Wu, X., Yuan, H., Wang, G., Li, S. and Wu, G., 2019. Impacts of lean construction on safety systems: A system dynamics approach. International journal of environmental research and public health, 16(2), p.221. https://doi.org/10.3390/ijerph16020221.

Xiang, J., Bi, P., Pisaniello, D., Hansen, A. and Sullivan, T., 2014. Association between high temperature and work-related injuries in Adelaide, South Australia, 2001-2010. Occup Environ Med, 71(4), pp.246-252.

Yi, W. and Chan, A., 2016. Health Profile of Construction Workers in Hong Kong. International journal of environmental research and public health, 13(12), p.1232.

Yi, W., and Chan, Albert, P.C. (2017). Effects of Heat Stress on Construction Labor Productivity in Hong Kong: A Case Study of Rebar Workers. International Journal of Environmental Research and Public Health. DOI: 10.3390/ijerph14091055. 
Zohar, D., 2002. Modifying supervisory practices to improve subunit safety: a leadership-based intervention model. Journal of Applied Psychology 87 (1), 156-163. 